NBER WORKING PAPER SERIES

\title{
THE IMPLICATIONS OF FIRST-ORDER \\ RISK AVERSION FOR ASSET \\ MARKET RISK PREMIUMS
}

\section{Geert Bekaert}

Robert J. Hodrick

David A. Marshall

Working Paper No. 4624

\section{NATIONAL BUREAU OF ECONOMIC RESEARCH \\ 1050 Massachusetts Avenue \\ Cambridge, MA 02138 \\ January, 1994}

This paper is part of NBER's research program in Asset Pricing. Any opinions expressed are those of the authors and not those of the National Bureau of Economic Research. 


\title{
THE IMPLICATIONS OF FIRST-ORDER \\ RISK AVERSION FOR ASSET \\ MARKET RISK PREMIUMS
}

\begin{abstract}
Existing general equilibrium models based on traditional expected utility preferences have been unable to explain the excess return predictability observed in equity markets, bond markets. and foreign exchange markets. In this paper, we abandon the expected-utility hypothesis in favor of preferences that exhibit first-order risk aversion. We incorporate these preferences into a general equilibrium two-country monetary model, solve the model numerically, and compare the quantitative implications of the model to estimates obtained from U.S. and Japanese data for equity, bond and foreign exchange markets. Although increasing the degree of first-order risk aversion substantially increases excess return predictability, the model remains incapable of generating excess return predictability sufficiently large to match the data. We conclude that the observed patterns of excess return predictability are unlikely to be explained purely by timevarying risk premiums generated by highly risk averse agents in a complete markets economy.
\end{abstract}

Geert Bekaert

Graduate School of Business

Stanford University

Stanford, CA 94305
Robert J. Hodrick

Kellogg Graduate School of Management

Northwestern University

Evanston, IL 60208

and NBER
David A. Marshall

Kellogg Gractuate School of Management Northwestern University Evanston, IL 60208 


\section{Introduction}

It is generally accepted that excess returns on a variety of assets are predictable. This is true for returns in the equity markets, bond markets, and foreign exchange markets of various countries. One interpretation of this evidence is that equilibrium risk premiums on all assets are highly variable. Yet, existing rational expectations general equilibrium models based on traditional expected utility preferences have been unable to generate risk premiums that are sufficiently variable to be consistent with the observed predictability of returns.

Consequently, in this paper we abandon the expected-utility hypothesis in favor of preferences that exhibit first-order risk aversion. ${ }^{1}$ With these preferences, agents are substantively averse to even small gambles. Hence, a small degree of uncertainty in the exogenous environment of economic agents can potentially induce relatively large fluctuations in agents' intertemporal marginal rates of substitution. This, in turn, implies large fluctuations in expected rates of return on a variety of assets. Our goal is to determine whether a general equilibrium model incorporating preferences that exhibit furst-order risk aversion is quantitatively consistent with the predictability of returns and with other time series properties observed in the data from the foreign exchange market, the equity markets, and the bond markets of the U.S. and Japan.

Other papers that propose first-order risk aversion as an explanation for asset pricing anomalies include Epstein and Zin $(1990,1991)$ and Bonomo and Garcia (1993). In particular, Epstein and Zin (1991) are unable to reject the overidentifying restrictions implied by a closed economy model, analogous to the model of Hansen and Singleton (1982), when first-order risk

1 The concept of first-order risk aversion was introduced by Segal and Spivak (1990). 
aversion is assumed. Their approach requires the researcher to choose a proxy for the unobservable rate of retum on aggregate wealth, and their inference about the validity of the model depends on this choice. In an open economy setting, the choice of a proxy for the retum on aggregate wealth is problematic. Hence, we do not follow the approach of Epstein and Zin (1991). Instead of testing the first-order conditions of the model, we explicitly solve a twocountry monetary model for the endogenous moments of interest.

In our model, consumption of two goods equals the outputs of two countries, which are assumed to be exogenous endowment streams. The two money supplies are also exogenous. The growth rates of these exogenous processes follow a discrete Markov chain that is estimated from U.S and Japanese data using the method of Tauchen and Hussey (1991). The equilibrium processes for retums and other endogenous variables are found by numerically solving a system of Euler equations. Having solved the model, we generate a variety of statistics that provide evidence on the predictability of the model's retums. The performance of the model is evaluated by comparing these statistics to the corresponding statistics in the data.

The remainder of the paper is organized as follows. In section 2, we present evidence on the predictability of excess rates of return in the dollar-yen foreign exchange market, in the dollar and yen discount bond markets, and in the equity markets. These stylized facts provide the set of statistics that we would like the model to match. In section 3, we discuss intuitively why time-varying equilibrium risk premiums could be an explanation of the statistics described in section 2. Section 4 introduces the concept of first-order risk aversion, and section 5 incorporates these preferences into a formal dynamic model. In section 6 we derive the model's equilibrium conditions for endogenous financial variables. Section 7 describes our procedure for 
calibrating the model, and section 8 presents our results. Section 9 compares our results with Epstein and $\operatorname{Zin}(1991)$, and section 10 provides concluding comments.

\section{Some Stylized Facts on Excess Return Predictability}

In this section we document the predictability of excess rates of return on discount bonds, equities, and foreign money markets using regression analysis. Since U.S. and Japanese data are the exogenous processes of the model, we report results only for these two countries. Nevertheless, the evidence is consistent across the markets of most developed countries as documented by the recent empirical studies of Harvey (1991), Bekaert and Hodrick (1992, 1993). and Solnik (1993), among others.

We begin by developing notation for own-country money market and equity investments. Let $R_{1}^{*}\left(I_{1}^{y}\right)$ be the dollar (yen) return at time $t+1$ from investing one dollar (yen) at time $t$ in the nominally risk-free dollar (yen) bond. Let $R_{i+1}^{s}\left(R_{t+1}^{y}\right)$ be the analogous one-period dollar (yen) return in the equity market of the U.S. (Japan). Throughout the paper, lower case letters will represent either the natural logarithms of upper case counterparts or variables measured as continuously compounded rates of return. Hence, the continuously compounded excess dollar (yen) rate of return in the U.S. (Japanese) equity market is $r_{1+1}^{s}-i_{1}^{s}\left(r_{1+1}^{y}-i_{1}^{y}\right)$. The conditional expectation of an excess return is often referred to in the literature as a risk premium, and we will use this terminology interchangeably with expected excess retum. ${ }^{2}$

\footnotetext{
${ }^{2}$ An excess rate of retum is the nominal rate of return on an asset in excess of the short-term interest rate. If inflation is stochastic, conditional expectations of excess rates of retum will be non-zero even if agents are risk neutral, which makes use of the term "risk premium" for these conditional expectations somewhat imprecise. Engel (1992) provides a recent discussion of this issue for the risk premium in the foreign exchange market.
} 


\section{A. The Foreign Exchange Market}

If $S_{t}$ is the spot exchange rate at date $t$ of dollars per yen, the dollar return to investing one dollar in the yen money market and bearing the foreign exchange risk is $S_{t+1} I_{t}^{*} / S_{r}$. Let $F_{t}$ be the forwand exchange rate of dollars per yen quoted at date $t$ for date $t+1$ transactions. Then, the dollar return to investing one dollar in the yen money market and eliminating the foreign exchange risk with a forward contract is $F_{1} Y_{q}^{*} / S_{v}$. Since this investment also provides a risk-free retum of dollars, covered interest arbitrage implies interest rate parity:

$$
i_{i}^{5}-i_{i}^{*}=f_{i}-s_{i} \text {. }
$$

The right-hand side of equation (1) is the continuously compounded forward premium or discount in the foreign exchange market. Notice that the continuously compounded excess dollar rate of retum from investing in the Japanese money market is $i_{1}^{*}+s_{t+1}-s_{1}-i_{t}^{s}$, which from equation (1) is $s_{t+1} \cdot \mathbf{f}_{\mathbf{r}}$.

A common way of testing the predictability of the excess rate of return on an uncovered foreign money market investment is to regress the excess return on the forward premium:

$$
s_{t+1}-f_{t}=\beta_{0}+\beta_{1}\left(f_{t}-s_{t}\right)+\varepsilon_{t+1} .
$$

The null hypothesis that the excess rate of return is unpredictable implies $\beta_{1}=0$. If the point estimate of $\beta_{1}$ differs significantly from zero, there is evidence that ex ante excess rates of return vary over time. In the empirical analysis we focus on a quarterly holding period since that is the 
frequency we use for the exogenous processes in simulating the model. ${ }^{3}$ The sample period for our exchange rate data is January 1976 to December 1989. The data are described more completely in Appendix A.

The first row of Table 1, Panel A, displays the regression results for equation (2) using the three-month forward premium as the predictor. As is typical in the literature, the slope coefficient of -4.016 is significantly negative. The $R^{2}$ for the regression is .22 , and the standard deviation of the fitted value of the excess retum, reported in Table 1, Panel B, is 12.36\%." These statistics indicate that excess returns are quite predictable and risk premiums are quite variable.

\section{B. The Discount Bond Market}

Similar evidence of predictable excess holding period rates of return can be found in the discount bond market using a forward premium computed from bond prices as a predictor. Specifically, let $V_{1, k}$ denote the date $t$ price of a nominally risk-free pure discount bond which pays one unit of currency at date $t+k$. When necessary to avoid confusion, there will be a superscript $\$$ or $¥$ symbol on $V_{1, k}$ to denote the currency. Let $i_{1, k}$ be the continuously compounded yield to maturity on a k-period bond expressed in percent per period. By definition,

\footnotetext{
${ }^{3}$ The availability of monthly observations on the three-month holding period allows us to use additional observations that increase the power of the tests but induce autocorrelation in the errors. As in Hansen and Hodrick (1980), the standard errors in Table 1 allow for the autocorrelation induced by the overlapping error structure and, additionally, for possible conditional heteroskedasticity as in Hansen (1982).

4 For the doilar values of other major foreign currencies, the estimated coefficients are also significantly below zero. Similar results arise in regressions using non-dollar exchange rates as demonstrated in Bekaert (1992) and Hodrick (1992). Bossaerts and Hillion (1991) use French franc exchange rates and find slope coefficients that are all less than zero, but not all are significantly negative.

5 All rates of retum in this paper are expressed in percentage points per annum.
} 


$$
v_{4}=\exp \left(-k i_{4}\right)
$$

Let the one-period continuously compounded holding period rate of return on a k-period bond realized at time $t+1$ be $h_{t+1 k}=\ln \left(V_{t+1 k-1} / N_{t, 1}\right)$, which from equation (3) can be written as

$$
h_{1+1, k}=-(k-1) i_{\mid+1, k-1}+k i_{u} .
$$

In the empirical analysis we examine the one-period excess holding period rate of return on a two-period bond, $h_{7+12}-i_{v}$ in a regression analogous to equation (2). For parallel structure, we define the forward premium in the bond market, denoted $f_{b}$, as the logarithm of the contractual price today for a one-period bond delivered one period from now minus the logarithm of the price today of a one-period bond:

$$
f b_{1}=\ln \left(V_{42} / V_{4,1}\right)-\ln \left(V_{10}\right)=-2 i_{1,2}+2 i_{1} .
$$

The bond market analogue to equation (2) is

$$
h_{1+1,2}-i_{1}=\beta_{0}+\beta_{1}\left(f b_{1}\right)+\varepsilon_{1+1} \text {. }
$$

If excess holding period returns are unpredictable, $\beta_{1}$ should be zero.

In rows two and three of Table 1, we report estimates of equation (6) for the U.S. dollar and Japanese yen discount bond markets. Since our timing interval is one quarter, $h_{t+1,2}$ is the three-month return on a six-month bond and $\mathrm{fb}_{\mathrm{l}}$ is the forward premium on a three-month bond to be purchased three months in the future. For the empirical analysis we have monthly observations on three-month and six-month Euro-dollar and Euro-yen interest rates from October 1975 to June 1990.

For both the dollar and the yen markets, the estimate of $\beta_{1}$ is -0.45 , and both are 
significantly negative. ${ }^{6}$ While the estimated $\beta_{1}$ 's are not as negative as the estimates from the foreign exchange market, there is strong evidence of predictability of the excess rates of return. The $R^{2}$ for the U.S. market is .03 , and the $R^{2}$ for the yen market is .09 . The standard deviations of the fitted values of the excess returns in the two markets are $0.318 \%$ for the U.S. and $0.370 \%$ for Japan. These statistics are much smaller than those in the foreign exchange market.

\section{The Equity Markets}

A similar set of results emerges from examining excess rates of return in equity markets. We focus on results in Bekaert and Hodrick (1992), who show that excess rates of return to U.S. and foreign equities are predicted by the forward premium in the foreign exchange market. Consistent with our two-country framework, we construct a dollar world equity market excess rate of return as an equally-weighted average of the dollar excess rates of returns on the equity markets of the U.S. and Japan:

$$
r_{1+1}^{*}-i_{1}^{s}=\left[\left(r_{t+1}^{s}-i_{1}^{s}\right)+\left(r_{1+1}^{v}-i_{1}^{v}\right)+\left(s_{1+1}-f_{1}\right)\right](1 / 2) \text {. }
$$

We regress this excess return on the three-month forward premium in the dollar-yen foreign exchange market:

$$
r_{1+1}{ }^{\prime \prime}-i_{1}^{s}=\beta_{0}+\beta_{1}\left(f_{t}-s_{1}\right)+\varepsilon_{t+1} .
$$

The fourth row of Table 1, Panel A, reports a slope coefficient of -3.543 , with a standard error of 0.816 . As equation (7) indicates, there are three components to this world equity excess rate of return: the excess dollar rate of return in the U.S. equity market, the excess yen rate of return in the Japanese equity market, and the excess rate of return in the foreign exchange market. The

\footnotetext{
6 These results are similar to those reported by Fama (1984b) and Stambaugh (1988) for monthly U.S. data.
} 
regression of the third component on the forward premium is discussed above. Regressions of the furst two components on the forward premium are contained in rows five and six of Table 1, Panel A. Each of the components has a negative slope coefficient, and all but the Japanese equity coefficient are significantly negative.

\section{Time-Varying Risk Premiums}

The patterns of predictability in excess returns documented above can, in principle, be

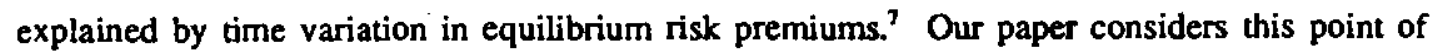
view. In this section we formally relate the regression evidence of the previous section to timevariation in risk premiums using a decomposition of the forward premium introduced by Fama (1984a). We then discuss what is required from an equilibrium model if it is to be consistent with the patterns observed in the data. ${ }^{3}$

Define the logarithmic risk premium in the foreign exchange market as $r_{t} \equiv E_{i}\left(s_{t+1}\right)-f_{1}$. Following Fama (1984a), the forward premium can be decomposed into the expected rate of

\footnotetext{
${ }^{7}$ The literature modelling asset retums as the outcome of a dynamic, stochastic equilibrium is too vast to be reviewed here. Examples of recent papers that model excess retums in foreign exchange markets using approaches related to that used in this paper include Backus, Gregory, and Telmer (1992), Bansal, Gallant, Hussey and Tauchen (1991), and Bekaen (1993a,b). Kandel and Stambaugh (1991) use a similar approach to model excess retums in equity markets.

- There are at least two other potential explanations of the data, which we take seriously but do not pursue in this paper. First, the stylized facts may not be representative of the true population distributions. Rather. they may be examples of problems in statistical inference caused by the adoption of a rational expectations perspective in non-experimental data. Such problems could be caused by infrequent regime changes, leaming, peso problems, data snooping biases, and so forth. Second, these stylized facts may be evidence of market inefficiency.
} 
depreciation of the dollar relative to the yen minus this risk premium:

$$
f p_{1} \equiv f_{1}-s_{1}=E_{1}\left(\Delta s_{i+1}\right)-r p_{1}
$$

where $\Delta$ is the first difference operator.

Now, consider the regression of $s_{t+1}-f_{t}$ on a constant and $f_{1}$, as in equation (2). By rational expectations, $s_{t+1}-f_{t}=r p_{t}+\varepsilon_{t+1}$, where the innovation, $\varepsilon_{t+1}$, is orthogonal to the time $t$ information set. Consequently, only the risk premium covaries with the regressor in equation (2), and the slope coefficient in that regression is

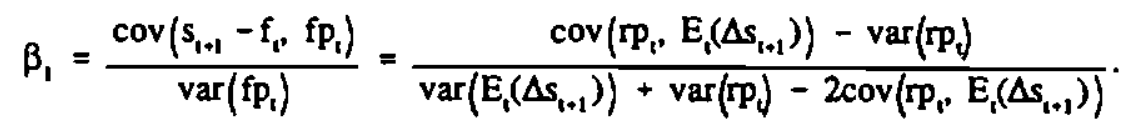

A decomposition similar to equation (9) can be performed for the bond market. Define the risk premium in the bond market to be $t_{1} \equiv E_{1}\left(h_{t+1,2}-i_{1}\right)$. Then, the forward premium in the bond market, $\mathrm{fb}_{1}$, can be decomposed into the expected rate of change of the logarithm of the one-period bond price minus the risk premium:

$$
\mathrm{fb}_{1}=\mathrm{E}_{\mathrm{l}}\left(\Delta \mathrm{v}_{\mathrm{t}+1}\right)-\mathrm{tb}_{\mathrm{t}} \text {. }
$$

where $v_{t+1}=\ln \left(V_{t+1}\right)$. The slope coefficient in equation (6) would then be given by an expression analogous to equation (10) with $\mathrm{T}_{\mathrm{t}}$ replaced by $\mathrm{r}_{\mathrm{t}}$ and $\Delta \mathrm{s}_{\mathrm{t+1}}$ replaced by $\Delta \mathrm{v}_{\mathrm{t+1}}$.

Clearly, if $\operatorname{var}\left(\mathrm{rp}_{\mathrm{J}}\right)=0$, the slope coefficient in equation (2) is zero. Similarly, if $\operatorname{var}\left(\mathrm{rb}_{\mathfrak{l}}\right)$ $=0$, the slope coefficient in equation (6) is zero. To generate the negative slope coefficients found in the data, the risk premiums $\mathrm{r}_{\mathrm{l}}$ and $\mathrm{t}_{\mathrm{l}}$ must vary through time. The decomposition (10) provides intuition regarding the amount of time-variation in risk premiums required to match the data. Consider first the case of foreign exchange. The explained variance in regression (2) is $\beta_{1}^{2} \operatorname{var}\left(\mathrm{fp}_{\mathrm{f}}\right)$, so the finding of $\beta_{1}<-1$ implies 


$$
\operatorname{var}\left(\mathbf{p}_{1}\right)>\operatorname{var}\left(\mathrm{f}_{\mathrm{p}_{1}}\right)
$$

Furthermore, if $\beta_{1}<-1$, equation (10) implies

$$
\operatorname{var}\left(\mathrm{p}_{1}\right)>\operatorname{cov}\left(\mathrm{p}_{\mathrm{t}}, \mathrm{E}_{\mathrm{l}}\left(\Delta \mathrm{s}_{\mathrm{t+1}}\right)\right)>\operatorname{var}\left(\mathrm{E}_{\mathrm{l}}\left(\Delta \mathrm{s}_{\mathrm{l+1}}\right)\right)
$$

Hence, regression results like those in the actual data require that the risk premium in the foreign exchange market be more variable than the expected rate of depreciation and that the risk premium and the expected rate of depreciation covary positively. Similarly, since the slope coefficient for the equity market regression is comparable to that in the foreign exchange market regression, the implied variability of the equity risk premium is comparable to the implied variability of the risk premium in the foreign exchange market.

In the case of the bond market regressions (6), the estimated slope coefficients are insignificantly different from -0.5 . Equation (10), applied to the dollar and yen bond markets, then implies

$$
\operatorname{var}\left(E_{1}\left(\Delta v_{t+1}\right)\right) \Rightarrow \operatorname{var}\left(b_{1}\right)
$$

That is, the variabilities of the risk premiums in the two bond markets are roughly equal to the variabilities of the expected rates of change of the logarithmic bond prices.

The general asset pricing framework of Hansen and Richard (1987) provides insight into what is needed from an equilibrium model if it is to generate the requisite time-variation in risk premiums. Let $R_{i, n+1}^{s}$ denote an arbitrary dollar retum realized in period $t+1$ from investing one dollar at time t. Hansen and Richard (1987) show that there exists a stochastic discount factor, 
$Q_{t+1}^{s}$, satisfying':

$$
E_{\mathrm{t}}\left[Q_{+1}^{s} R_{t+1}^{s}\right]=1 \text {. }
$$

In equilibrium models with effectively complete markets, $Q_{t+1}^{s}$ equals each agent's intertemporal marginal rate of substitution of wealth divided by the gross rate of change in the dollar price level.

Equation (15) implies that substantial time variability in excess returns can be achieved only if there is substantial time-variation in the conditional second moments of the joint $\left(R_{t,+1}^{3}\right.$, $Q_{i+1}^{s} l$ process, which, in turn, requires substantial volatility in the marginal rate of substitution. ${ }^{10}$ One way of generating highly volatile marginal rates of substitution is to assume that agents have a high degree of risk aversion. In effect, the extreme nonlinearity associated with high risk aversion can transform the uncertainty due to conditionally homoskedastic exogenous inputs into endogenous risky asset returns whose moments are conditionally quite variable. Alternatively, high volatility in marginal rates of substitution can be generated by directly assuming timevarying conditional heteroskedasticity in the exogenous driving processes (as in Bekaert (1993b))."

It should be noted that increasing the variance of risk premiums is not sufficient to insure

\footnotetext{
${ }^{9}$ Hansen and Richard (1987) require that (i) the space of portfolio payoffs is a Hilbert space of square integrable random variables, and (ii) there are no arbitrage opportunities.

10 Hansen and Jagannathan (1991) develop restrictions on the mean and variance of the Intertemporal marginal rate of substitution implied by the stochastic properties of observed asset returns. Cochrane and Hansen (1992) use this methodology to survey equilibrium approaches to asset pricing. They demonstrate how difficult it is to generate sufficient variability in $Q_{i+1}^{3}$ within the context of an equilibrium model.

'In principle, these two approaches could be combined. For the model of this paper, however, incorporating time-varying conditional heteroskedasticity substantially increases the dimensionality of the state space, rendering the approach computationally intractable.
} 
that conditions (12), (13), and (14) hold. The forward premiums and the expected rates of change of asset prices are also endogenous variables in the model. Changes in the model specification that increase the variances of risk premiums may also increase the variances of $\mathrm{E}_{1}\left(\Delta \mathrm{s}_{t+1}\right)$ and $\mathrm{E}_{\mathrm{l}}\left[\Delta \mathrm{v}_{\mathrm{t}+1}\right]$, leaving the relative variances unchanged. Furthermore, the covariances between the risk premiums and the expected rates of change of asset prices may change. Thus, while it is likely that extreme risk aversion will increase the variability in intertemporal marginal rates of substitution, it is unclear whether this is sufficient to induce the patterns of predictability in excess returns that are observed in the data. Hence, to explore the effects of increasing risk aversion we must solve the model explicitly.

\section{First-Order Risk Aversion}

The preceding discussion makes clear the role that substantial risk aversion may play in generating the regression results described in section 2 . Models using expected-utility preferences have not fared well in this regard. Even the models of Backus, Gregory, and Telmer (1993) and Bekaert (1993b), which incorporate substantial time-nonseparabilities in the form of habit persistence, fail to imply sufficient predictability in excess rates of return. The reason for this failure is not difficult to see. Expected-utility preferences display second-order risk aversion. That is, in response to a lottery which is close to perfect certainty, an expected utility maximizer exhibits behavior close to risk neutrality. This is a problem for consumption-based asset pricing models because, at any given date, the conditional variance of next period's aggregate consumption is small.

One way of addressing this problem is to abandon preferences that display only secondorder risk aversion in favor of preferences that imply first-order risk aversion. With this type of 
preference specification, agents are substantially averse to even small gambles. Epstein and Zin (1991) examine a variety of such preferences, including Gul's (1991) disappointment aversion preferences, in order to increase the variability of agents intertemporal marginal rate of substitution. Disappointment aversion was introduced by Gul (1991) as a way of accommodating the Allais paradox within a parsimonious extension of expected utility. Camerer's (1989) review of the experimental economics literature suggests that expected utility cannot explain the experimental evidence on preference orderings under uncertainty. Rather, what is required is a preference ordering in which outcomes are evaluated relative to some reference point. Disappointment aversion has this property.

We follow Epstein and Zin (1991) in using the following simple model of disappointment aversion. A preference ordering over the space of probability distributions $\mathfrak{P}$ (e.g., over alternative lotteries) can be represented by a certainty equivalent function $\mu: \mathcal{P} \rightarrow \mathbf{R} \quad$ For $P \in \mathcal{P}$, $\mu(P)$ is implicitly defined by

$$
\frac{\mu(P)^{\alpha}}{\alpha} \equiv \frac{1}{K}\left(\int_{(-\infty, \mu(P)]} \frac{z^{\alpha}}{\alpha} d P(z)+A \int_{\left.(\mu P)_{1}, \infty\right)} \frac{z^{\alpha}}{\alpha} d P(z)\right), A \leq 1, \alpha<1 .
$$

where $K=A \operatorname{prob}(z>\mu)+\operatorname{prob}(z \leq \mu)$. If $A=1$, the preferences described by equation (16) correspond to expected utility with a coefficient of relative risk aversion equal to $1-\alpha$. If $A$ differs from unity, equation (16) can be interpreted as follows. Those outcomes below the certainty equivalent are disappointing, while those above the certainty equivalent are elating. If $A<1$, the elation region is down-weighted relative to the disappointment region. The next section embeds these preferences in a two-country monetary model.

\section{A Two-Country Monetary Model}


In the model asset prices and exchange rates are determined in a competitive equilibrium in which the demands for assets and goods are the optimal choices of a representative agent. As in Marshall (1992) and Bekaer (1993b), money is demanded by agents because consumption transactions are costly, and increasing real balance holdings decreases these transaction costs. Specifically, let the two countries be denoted as $x$ and $y$, respectively. The representative agent's consumption of the good produced in country $\mathrm{x}$ is $\mathrm{c}^{\mathrm{x}}$, and the representative agent's consumption of the good produced in country $y$ is $c^{y}$. Consumption of $c^{x}$ involves transaction costs measured by

$$
\psi_{1}^{x} \equiv \psi^{x}\left(c_{t}{ }^{x}, M_{t+1}^{x} / P_{t}^{x}\right) \equiv \lambda\left(c_{1}{ }^{x}\right)^{v}\left(M_{t+1}^{x} / P_{t}^{x}\right)^{1-v}, v>1, \lambda>0,
$$

denominated in units of $c^{x}$, where $M_{t+1}^{x}$ is the amount of currency $x$ (which we call the dollar) acquired by the representative agent in period $t$ and $P_{t}^{x}$ is the price of $c^{x}$ at date $t$ in units of $M^{x}$. Consumption of $c^{y}$ involves a transaction cost of

$$
\psi_{1}^{y} \equiv \psi^{y}\left(c_{1}^{y}, M_{1+1}^{y} / P_{1}^{y}\right) \equiv \zeta\left(c_{1}^{y}\right)^{\xi}\left(M_{1+1}^{y} / P_{1}^{y}\right)^{1-\xi}, \xi>1, \zeta>0
$$

denominated in units of good $y$, where $M_{t+1}^{y}$ is the amount of currency $y$ (which we call the yen) acquired by the representative agent in period $t$; and $P_{1}^{y}$ is the yen price of $c^{y}$ at date $t$.

The timing in this model differs from the transaction-cost models of Feenstra (1986) and Marshall (1992) in that money provides transaction services in period $t$ when it is acquired. However, money must be held until the following period, so losses in purchasing power due to inflation accrue in period $t+1$. This timing is imposed for tractability. With our timing, the only endogenous state variable affecting an individual agent's decisions is the agent's stock of wealth. 
If money only provided transaction services if acquired one period earlier, the agent's stock of money would represent a second endogenous state variable. The optimality conditions would then involve the derivatives of the (unknown) value function with respect to the money-wealth ratio. To solve such a model numerically would be extremely burdensome computationally.

In addition to monies, agents can hold $n$ capital assets. Let $z_{i+1}$ be the value (in units of $c^{\pi}$ ) of the representative agent's investment in asset $i$, chosen at $t$, and which pays off at $t+1$. The gross real return to asset $i$ (measured in units of good $x$ received in $1+1$ per unit of good $x$ invested at date $t$ ) is denoted $R_{\mathrm{L}+1}$.

If $S_{1}$ denotes the exchange rate (dollars/yen), the budget constraint for the representative agent in units of consumption good $x$ is

$$
c_{1}{ }^{x}+\psi_{1}^{x}+\frac{S_{1} P_{1}^{y}}{P_{1}^{x}}\left(c_{1}^{y}+\psi_{1}^{y}\right)+\sum_{i=1}^{D} z_{L+1}+\frac{M_{1+1}^{x}+S_{1} M_{1+1}^{y}}{P_{1}^{x}} \leq W_{1}
$$

where $W_{1}$ denotes the representative agent's wealth at the beginning of period $t$ :

$$
W_{1} \equiv \frac{M_{1}^{x}+S_{1} M_{1}^{y}}{P_{1}^{x}}+\sum_{i=1}^{e} z_{i t} R_{i t}
$$

The representative agent's preferences over current and uncertain future consumption incorporate disappointment aversion as in equation (16), and are specified using the approach of Epstein and Zin (1989). Specifically, let $J_{1}$ denote the vector of exogenous state variables which span the agent's information set at date $t$. The utility value of $W_{1}$ in the state $J_{1}$ is denoted $V\left(W_{1}\right.$, $J$, and is defined recursively by 


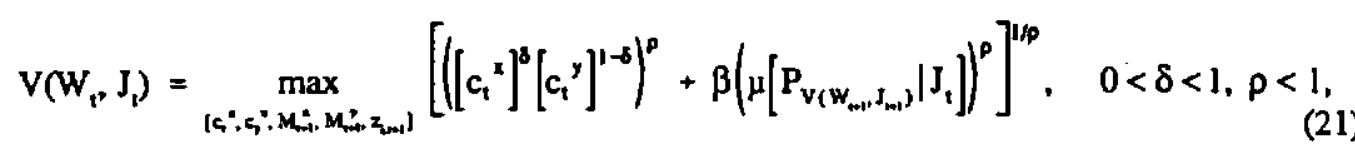

subject to the budget constraint (19) and the wealth constraint (20), using the definition of $\mu$ from equation (16). The expression $p\left[P_{\mathrm{v}\left(w_{w, j}, J_{w}\right)} \mid J_{1}\right]$ denotes the certainty equivalent of the conditional distribution of the value function at date $t+1$, given information at date $t$. When agents make their consumption and portfolio choices, they care about two distinct effects: how their choices affect current-period utility, and what happens to the probability distribution of their future utility. In an expected utility framework, the latter effect is incorporated by taking the conditional expectation of next-period's value function. In equation (21), effects of the probability distribution of future utility on current utility are captured by the cerainty equivalent function $\mu$. In addition, the two effects are aggregated in equation (21) by the CES function of the form $\left(a^{p}+b^{p}\right)^{[1 / p]}$, while, in the expected-utility framework, the two effects are simply added.

The parameter $\rho$ governs intertemporal substitution in the following, somewhat unconventional, sense: The elasticity of substitution between current utility $\left(c^{x}\right)^{8}\left(c^{1}\right)^{1-b}$ and the

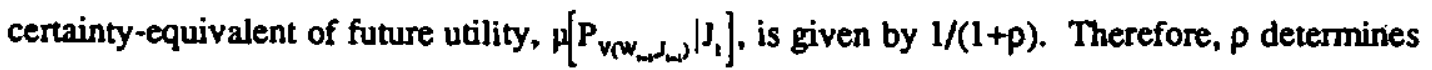
the optimal tradeoff between present and future utility. When $\rho$ is near unity, there is an extremely high degree of substitutability between these two sources of utility. Extremely negative values of $p$ imply almost no substitutability. It should be noted that this elasticity of substitution does not directly correspond to the elasticity of substitution between current and future consumption (as studied, for example, by Hall (1988)). The more conventional notion of 
intertemporal substitution elasticity is a function of all the preference parameters of the model.

\section{Equilibrium Determination of Exchange Rates and Asset Returns}

In order to derive equilibrium asset prices and exchange rates, we must solve the representative agent's decision problem and impose market clearing. The agent's optimal behavior is characterized by a set of Euler equations that involve the real return on optimallyinvested aggregate wealth, which we denote $R_{r}$. (An explicit characterization of $R_{1}$ can be found in Appendix B.) These equations also involve the real returns, inclusive of marginal transaction cost savings, from holding dollars and yen. Let

$$
\left.R_{x, 1+1} \equiv\left(\frac{P_{1}^{2}}{P_{t+1}^{2}}\right) \frac{1}{1+\psi_{2 x}^{2}}\right)
$$

denote the real return from holding dollars, where $\psi_{\mathrm{i}}^{\mathrm{x}}$ denotes the period $t$ partial derivative of $\Psi_{i}^{x}$ with respect to its $i^{\text {tb }}$ argument. ( $\psi_{i 1}^{y}$ is defined similarly.) The real retum from holding yen is

$$
\left.R_{j,+1} \equiv\left(\frac{S_{t+1} P_{t}^{2}}{S_{t} P_{1+1}^{2}}\right) \frac{1}{1+\psi_{2 x}^{y}}\right) .
$$

Note that both $R_{2,+1}$ and $R_{y, n+1}$ are measured in units of good $x$ received in $t+1$ per unit of good $\mathbf{x}$ invested at date $\mathbf{t}$.

The first-order conditions for the representative agent's optimal consumption, money holdings, and portfolio choices are the following: ${ }^{12}$ request.

12 The derivation is a modification of the arguments in Epstein and Zin (1989), and is available upon 


$$
\begin{gathered}
E_{1}\left\{I_{A}\left(Z_{1+1}\right)\left\{Z_{i+1}^{a}-1\right]\right\}=0, \\
E\left[I_{A}\left(Z_{1+1}\right) Z_{i+1}^{a} R_{i+1}^{-1} R_{1,+1+1}\right]=E_{1}\left[I_{A}\left(Z_{1+1}\right)\right], \forall i=x_{1}, 1, \ldots N,
\end{gathered}
$$

where

$$
Z_{1+1} \equiv\left[\beta\left(\frac{c_{1+1}^{x}}{c_{1}^{x}}\right)^{\rho \delta-1}\left(\frac{c_{1+1}^{y}}{c_{1}^{y}}\right)^{\alpha(1-\delta)}\left(\frac{1+\psi_{11}^{x}}{1+\psi_{11+1}^{x}}\right) R_{1+1}\right]^{\alpha / \rho},
$$

and

$$
I_{\wedge}(Z) \equiv\left\{\begin{array}{l}
A \text { if } Z \geq 1 \\
1 \text { if } Z<1
\end{array} .\right.
$$

In developing the solution to the model, it is useful to define the endogenous processes for consumption-velocities of the two monies. Let $v_{1}^{x}$ and $v_{1}^{y}$ denote the consumption-velocities in countries $x$ and $y$ :

$$
v_{1}^{x} \equiv \frac{c_{1}^{x} P_{1}^{x}}{M_{1+1}^{x}} ; \quad v_{1}^{y} \equiv \frac{c_{1}^{y} P_{1}^{y}}{M_{1+1}^{y}}
$$

Other endogenous variables are the nominally risk free, continuously compounded interest rates on dollars and yen, denoted $i_{1}^{s}$ and $i_{i}^{Y}$ Nominally risk-free interest rates are functions of the marginal transaction costs with respect to real balances:

$$
i_{1}^{s}=\ln \left(\frac{1}{1+\psi_{21}^{a}}\right) ; \quad i_{1}^{y}=\ln \left(\frac{1}{1+\psi_{21}^{y}}\right) .
$$

The exchange rate $S_{1}$ is given by 


$$
S_{1}=\frac{P_{1}^{x}}{P_{1}^{y}}\left(\frac{1+\psi_{11}^{x}}{1+\psi_{11}^{y}}\right)\left(\frac{c_{1}^{x}}{c_{1}^{y}}\right)\left(\frac{1-\delta}{\delta}\right) .
$$

Given interest rates and the spot rate, the forward rate $F_{1}$ can then be computed using covered interest parity as in equation (1).

\section{Calibration and Solution of the Model}

In this section we describe our procedures for choosing the parameters of the stochastic processes for the exogenous variables and of the transaction cost functions. The outputs and money supplies of the two countries are assumed to be exogenous. There are no data series corresponding precisely to the endowment constructs of the model. The difficulty is that a twocountry model cannot replicate the complexity of trade patterns that we observe in the real world. As a result, we do not take seriously the predictions of the model for quantity variables. However, the implications of the model for asset retum predictability can be investigated with a plausible specification of the endowment driving processes.

We calibrate the endowments and money supplies of the two countries to consumption data and money supply data from the U.S. and Japan. The growth rates of these four exogenous processes are assumed to follow a vector autoregression, which we will approximate as a discrete Markov chain. We find that a first-order VAR with conditionally homoskedastic errors fits the data well. In Table 2, Panels A and B, we display OLS estimates of this VAR. Table 2, Panel C reports statistics testing the appropriate lag length for the VAR. The Akaike and Schwarz criteria, as well as the sequential likelihood ratio tests, support the first-onder VAR specification. Table 2, Panel D provides statistics testing for normality, autocorrelation, and conditional homoskedasticity of the VAR residuals. Only in the residual for the growth rate of Japanese 
consumption is there marginal evidence of serial correlation. For none of the residuals is there significant evidence against normality or conditional homoskedasticity.

The growth rates of these four exogenous processes are approximated by a discrete firstorder Markov chain in which each variable can take four possible values, implying a state space with 256 possible values. The Markov chain is calibrated to the estimated VAR using the Gaussian quadrature method of Tauchen and Hussey (1991). In Table 3, we display the parameters of the first-order VAR implied by this Markov chain approximation. The parameters characterizing the Markov process VAR are virtually indistinguishable from those of the estimated VAR reported in Table 2. All parameters of the Markov process VAR (including the elements of the covariance matrix decomposition) are within one-tenth of one standard error of the corresponding parameters in the estimated VAR. We take this as evidence that the discrete approximation is unlikely to distort the economic implications of the model.

The parameters of the transaction cost functions (17) and (18) are chosen by fitting equations (29) to U.S. (for $\psi^{\gamma}$ ) and Japanese (for $\psi^{\gamma}$ ) data, as described in Appendix A. Specifically, we set

$$
\psi^{x}(c, m)=0.0008 c^{4.331} m^{1-4.331} ; \quad \psi^{y}(c, m)=0.0166 c^{2.109} m^{1-2.109}
$$

Given this exogenous process, the three unknown endogenous processes $R_{v}, v_{i}^{x}$, and $v_{1}^{j}$ are found by solving the three Euler equations (24) and (25) (for $i=x$ and $y$ ) simultaneously. Since the state space is discrete, the Euler equations can be solved exactly for the 256 values of each endogenous variable. The only approximation is in the initial discretization of the driving processes. A detailed description of the solution procedure can be found in Appendix B. Once $R_{r} v_{v}^{3}$, and $v_{1}^{j}$ have been determined, all other endogenous variables can be calculated from 
definitions and equilibrium conditions.

\section{Implications of the Model for Excess Return Predictability}

In this section, we report results obtained from solving the model for a variety of parameters governing preferences. The quarterly subjective discount parameter $\beta$ is fixed at $(0.96)^{0.25}$. The choice of $\delta$ (the weight on $c^{x}$ in the current-period utility) is irrelevant, since we examine rates of depreciation, rather than levels of exchange rates. The remaining parameters are varied over the following grid: $A \in(1.0,0.85,0.70,0.55,0.40,0.25\}, p \in[0.50,-0.33,-4.0$, -9.0 ). We experimented initially with values of $\alpha$ between 0.5 and -9 and found that the choice of $\alpha$ had virtually no effect on the moments of interest. Consequently, we only report results for $\alpha=-1$. This corresponds to a coefficient of relative risk aversion of 2 in an economy with expected-utility preferences over timeless gambles.

We first discuss the ability of the model to replicate the predictability of excess returns documented in section 2. We focus on three measures of predictability: the slope coefficient in the excess return regressions analogous to equations (2), (6), and (8); the $R^{2}$, measured as the ratio of the variance of the expected excess return to the variance of the realized excess retum; and the standard deviation of the expected excess return. All three statistics can be computed exactly given the discrete Markov chain driving process.

Consider the model's implications for the slope coefficients in the excess return regressions analogous to equations (2), (6), and (8). The results are displayed in Tables 4, 5, and 6 for the foreign exchange market and the dollar and yen discount bond markets, respectively. Table 7 displays the slope coefficient when the excess retum to the aggregate wealth portfolio (which we interpret as an analogue to an unlevered equity portfolio) is regressed on the foreign 
exchange forward premium.

It is clear from these tables that the model cannot match the slope coefficients estimated from observed data. For no combination of parameters do the regression coefficients implied by the model come close to the magnitudes reported in Table 1. For example, for the foreign exchange market regression, the estimated slope coefficient in Table 1 Panel A is -4.016 , with an estimated standard error of 0.766 . The most negative slope coefficient implied by the model is -0.191 , which is approximately five standard errors away from the estimated value. Similarly, the slope coefficients implied by the model for the term structure regressions analogous to equation (6) (reported in Tables 5 and 6) and the equity return regressions (reported in Table 7) are extremely small, and they are all more than 3.4 standard errors away from the corresponding estimates reported in Table 1.

The second measure of predictability is the model's $R^{2}$ as defined above. This theoretical $R^{2}$ cannot be observed in the data, but a lower bound is provided by the estimated $R^{2} s$ reported in Table 1, Panel A. Whereas the $R^{2} s$ in the data are substantive, ranging between $1 \%$ and $22 \%$, the corresponding $R^{2} s$ in the model are negligible, all being less than $.2 \%$.

The third measure of the predictability of excess returns is the variability of the explained component of excess returns. As with the $\mathrm{R}^{2}$ discussed above, a lower bound for this measure in the data is provided by the standard deviation of the fitted value of the excess return regressions reported in Table 1, Panel B. As with the previous two measures, the model is unable to reproduce the variability observed in the data. For example, the standard deviation of the fitted value of $s_{t+1}-f_{t}$ in Table 1 is $12.4 \%$. The largest value of the standard deviation of $E_{i}\left(s_{t+1}-\mathfrak{f}_{1}\right)$ from the model, reported in Table 4 , is $0.356 \%$, which is over thirty times too small. 
Analogously, the standard deviation of the fitted value of the excess world equity retum in Table 1 is $10.9 \%$. The largest standard deviation of $E_{1}\left(r_{t+1}-i_{l}\right)$ from the model, reported in Table 7 , is $0.175 \%$, which is over sixty times too small. The standard deviations of the fitted values of the excess returns in the discount bond markets are $0.318 \%$ and $0.370 \%$ for the dollar and the yen markets, respectively. The maximum value of the standard deviations of the expected excess returns, reported in Tables 5 and 6 , are $0.13 \%$ and $0.06 \%$ respectively.

These results are somewhat disappointing to those who favor risk-based explanations for the predictability of excess returns. To further explore the role of risk aversion in generating predictability in excess retums, we next examine how the predictions of the model change as we increase the importance of the first-order risk aversion by lowering $A$. In all cases, setting $A=$ 1 results in extremely small values for the slope coefficients. However, it is not generally true that increasing the amount of risk aversion (decreasing A) implies more negative slope coefficients. Furthermore, a large degree of risk aversion is not systematically associated with a particular sign of the regression coefficient. For example, the coefficients corresponding to $A$ $=.40$ and $\mathrm{A}=.25$ in Tables 4 through 7 are as likely to be positive as to be negative. Thus, even if it were assumed that agents in the economy display extreme risk aversion, it is not at all clear whether this would improve the performance of the model along this dimension.

To see why the model fails to replicate the observed slope coefficients, it is useful to return to the discussion of section 3. In that section, we argued that substantial time-variation in risk premiums is necessary if a model is to match the patterns found in the data. Examination of Tables 4 through 7 reveals that the variances of the ex ante risk premiums are unambiguously increasing as the degree of first-order risk aversion increases. For foreign exchange, the standard 
deviation of the risk premium increases by a factor of 100 when A moves from 1 to .25 . For discount bonds and the aggregate wealth portfolio, the standard deviation of the risk premium increases at least twenty-fold when A moves from 1 to .25 . Similarly, the $R^{21} s$ in all markets increase dramatically as first-order risk aversion is increased.

The reason why these dramatic increases in risk-premium volatility do not imply comparable increases in the magnitude of the slope coefficients in the prediction regressions is that these coefficients are functions of moments in addition to the variances of the risk premiums. As shown in equation (10), the slope coefficients also depend on the variances of the expected asset price changes and on the covariances between the expected changes in asset prices and the risk premiums. These moments are also affected by changes in the parameter governing firstorder risk aversion. In particular, Tables 5 and 6 show that the variances of the expected changes in the prices of one-period discount bonds actually decrease unambiguously as A decreases. The variance of the expected change in the spot foreign exchange rate is not monotonic in A. As shown in Table 4, decreasing A from unity initially reduces this variance, while further reductions in $\mathrm{A}$ increase it. The value of $\mathrm{A}$ at which this variance is at a minimum depends on p. The effects of increased first-order risk aversion on the covariances between the ex ante risk premiums and the expected changes in asset prices are also in Tables 4 through 6 . In the foreign exchange market, decreasing A unambiguously increases this covariance. In the discount bond markets, the response of this covariance to increased risk aversion is not monotonic, and depends on the value of $p$.

Our model also has implications for the unconditional mean equity premium and the unconditional standard deviations of financial variables, which provide additional dimensions to 
assess the model's performance. In Table 7, increasing the amount of first-order risk aversion dramatically increases the unconditional mean excess equity retum. As $A$ is reduced from 1 to .25 , the mean equity risk premium increases by a factor of approximately 20 . This increase is not sufficient to match the data as the largest mean equity premium generated by our model simulations is $3.5 \%$ : While this is substantially below the value of $8.4 \%$ estimated from our data set, the equity return data correspond to a levered portfolio, while the equity retum computed in our model is unlevered. The result are comparable to those of Bonomo and Garcia (1993) for homoskedastic driving processes. These authors are able to increase the mean equity risk premium significandly by employing a richer driving process that incorporates regime switching.

Table 8 displays standard deviations implied by the model. In comparing Table 8 with Table 1, Panel B, notice that the magnitudes of the standard deviations in the model are almost always smaller than the corresponding statistics in the data. In particular, the standard deviation of currency depreciation is approximately 2.5 times higher in the data than in the model, and the standard deviation of the equity risk premium is approximately three times higher in the data than in the model. When $\rho=-9$, the standard deviation of the forward premium in the model is only $50 \%$ lower than that in the data; for the other values of $\rho$, the variability of the forward premium is almost an order of magnitude too low.

Although the model underpredicts the variability of both expected and realized excess returns, the pararneterizations of the model that generate the largest variances of expected rates of retum tend to overpredict the variances of the forward premiums in the discount bond markets. For example, with $\rho=-9$ and $A=.25$, the standard deviations of the forward premiums in the dollar and yen discount bond market are $3.81 \%$ and $2.56 \%$, compared to $0.71 \%$ and $0.83 \%$ in 
Table 1, Panel B.

The source of this problem is as follows. In order to generate high volatility in excess returns, the model must generate high volatility in the conditional second moments of intertemporal marginal rates of substitution. Unfortunately, parameterizations of the model which do this also imply highly volatile spot interest rates. A similar problem has been noted in a closed-economy model by Heaton (1991). Consequently, one challenge for this class of models is to accommodate highly variable expected and realized excess returns on risky assets while keeping short-term interest rates relatively non-volatile.

\section{On the Success of Epstein and Zin (1991)}

Epstein and Zin (1991) are unable to reject the overidentifying restrictions implied by their single-country model with preferences incorporating first-order risk aversion, which suggests considerable support for this approach to asset pricing. Our approach is less successful. How can we explain the differences in findings?

According to the Euler equation (25), the implications of these models for asset returns are summarized in the behavior of the asset pricing operator

$$
\frac{I_{A}\left(Z_{+1}\right)}{E_{[}\left[1_{\Lambda}\left(Z_{+1}\right)\right]} Z_{++1}^{a} R_{+1}^{-1} \text {. }
$$

This operator is a function of $R_{1+1}$, the return to the aggregate wealth portfolio. Euler equation estimation requires an observable analogue to this asset pricing operator, and Epstein and Zin use the return on a value-weighted portfolio of equities as their empirical measure of $R_{1+1}$. This procedure is clearly subject to Roll's (1977) critique, a point acknowledged by Epstein and Zin. Furthermore, with this approach, the empirical asset pricing operator is a function of the returns 
on the equity assets being priced. The operator partially inherits the statistical properties of observed equity returns, so it has less difficulty replicating the behavior of observed excess equity returns. In contrast, we derive $R_{t+1}$ by explicitly solving the model's equilibrium as a function of the growth rates of output and money in the two countries. Nowhere do we use data on asset returns in deriving the asset pricing operator. To ask the pricing operator, derived in this way, to replicate the stochastic properies of equity returns is a much tougher test of the model than the Epstein-Zin procedure. It is not surprising that we find more eviderice against the model.

\section{Conclusions}

In this paper, we ask whether high levels of risk aversion can explain the observed predictability of excess returns within the context of a frictionless, representative agent model. In order to give this explanation the best chance for success, we assume that agents' preferences display first-order risk aversion. This preference specification implies that agents respond more strongly to consumption risk than would be the case under conventional Von NeumannMorgenstern preferences. Yet, even this more extreme form of risk aversion can explain only a small fraction of the predictability of excess returns found in the data. Furthermore, we find that the slope coefficients in equations predicting excess returns do not increase monotonically with increased risk aversion. The level of risk aversion affects not only the variability of risk premiums, but also the second moments of other endogenous variables which affect predictability. The resulting implications for the signs and magnitudes of these slope coefficients are ambiguous.

Taken together, the results of this paper suggest that the predictability of excess returns cannot be fully explained simply by modifying preference assumptions. A more promising approach may be to abandon the assumption that the empirical distribution in the data set is a 
good proxy for agents' subjective distribution over future variables. Rational optimizing models that do not impose this assumption include learning models, models with peso-problems, and some models with regime switching. It is hoped that these altemative approaches will have more success in explaining excess-return predictability than approaches based solely on modelling agents' aversion to consumption risk. 


\section{APPENDIX A： DESCRIPTION OF DATA}

The interest rate data are monthly series on three-month and six-month Euro-dollar and Euro-yen rates, obtained from the Harris Bank database at the University of Chicago. Monthly exchange rate data are from daily bid and ask rates from Citicorp Database Services and are described in detail in Bekaert and Hodrick (1993).

The money supplies for the U.S. and Japan are quarterly series taken from International Financial Statistics (IFS Series 34). Growth rates are deseasonalized by regressing on four dummies. The consumption data are Nondurables and Services from the OECD Quarterly National Accounts. The Japanese data include the Semi-durables category, as this category is included in the U.S. Nondurables series. Per capita data on money supplies and consumption were derived by using linear interpolations from the annual population series $99 \mathrm{z}$ from IFS.

The transaction cost technology parameters are considered to be part of the exogenous environment and are calibrated from the model's implications for money demand, as summarized by equations (29). These equations imply linear relationships between the logs of current dollar and yen velocities of circulation and the logs of the respective interest rate divided by one plus the interest rate. The calibration is done by linear regression using quarterly Eurocurrency interest data and nominal velocity. The velocity series used is computed using nominal GDP, taken from OECD Quarterly National Accounts, divided by the money series described above. GDP velocity is used because it implies more reasonable parameters for the transaction cost function than consumption velocity. The use of GDP velocity can be justified by noting that money in actual economies intermediates many more transactions than just consumption transactions. See Marshall (1992) for a fuller discussion of this issue. 


\section{APPENDIX B: SOLUTION PROCEDURE}

The key step in solving the model is to solve numerically the Euler equations (24) and (25) for the endogenous variables $v_{1}^{x}, v_{1}^{y}$, (defined in equations (28)) and $R_{t+1}$ (the return to the aggregate wealth portfolio). We do so by using a finite-state Markov chain to approximate the exogenous driving process (see Tauchen and Hussey (1991)). We then solve the model exactly for this approximate driving process. In this appendix we describe the solution procedure in greater detail.

Let $e_{1}^{x}$ denote the total output of good $x$ at date th, let $e_{1}^{y}$ denote the output of good $y$ at date $t$, and let $M_{t+1}^{T}$ and $M_{t+1}^{t}$ denote the supplies of dollars and yen respectively, available for use in mediating transactions at date $t$. (These money stocks are dated $t+1$ because it is assumed that the loss in value from inflation accrues to the agent in $t+1$.) Let $g$ denote the vector of growth rates of outputs and money supplies in the two countries:

$$
g_{2}=\left\{\frac{e_{1}^{x}}{e_{t-1}^{x}}, \frac{e_{1}^{y}}{c_{1-1}^{y}} \cdot \frac{M_{1+1}^{x}}{M_{1}^{x}}, \frac{M_{1+1}^{y}}{M_{1}^{y}}\right\} .
$$

It is assumed that $\left(e_{t}^{x}, e_{t}^{y}, M_{t+1}^{x}, M_{t+1}^{y}\right)$ is an exogenous process whose law of motion is known.

First, we show how equations (24) and (25) can be written in terms of $g$ and the three endogenous processes $\left(v_{t}^{x}, v_{1}^{y}, R_{t+1}\right\}$. Using (17), (18), and the requirement that, in equilibrium, the output of each good must either be consumed or used as transaction costs,

$$
e_{1}^{j}=c_{i}^{j}+\psi\left(c_{1}^{j},\left(M_{1+1}^{j} / P_{1}^{j}\right)\right), j=x, y,
$$

we can write consumption growths, marginal transaction costs, and inflation rates as functions of $\left\{g_{1}, v_{1}^{x}, v_{1}^{y}, R_{t+1}\right\}$ : 


$$
\begin{aligned}
& \frac{c_{t+1}^{2}}{c_{1}^{x}}=\frac{e_{t+1}^{x}}{e_{1}^{x}}\left[\frac{1+\lambda\left(v_{1}^{3}\right)^{v-1}}{1+\lambda\left(v_{1+1}^{3}\right)^{v-1}}\right] \\
& \frac{c_{t+1}^{y}}{c_{t}^{y}}=\frac{e_{i+1}^{y}}{e_{1}^{y}}\left[\frac{1+\zeta\left(v_{1}^{y}\right)^{\xi-1}}{1+\zeta\left(v_{t+1}^{y}\right)^{\xi-1}}\right] \\
& \psi_{11}^{x}=\lambda v\left(v_{1}{ }^{3}\right)^{v-1} \\
& \psi_{11}^{y}=\zeta \xi\left(v_{t}^{y}\right)^{\xi-1} \\
& \psi_{2}^{x}=\lambda(1-v)\left(v_{1}{ }^{x}\right)^{v} \\
& \psi_{2 z}^{y}=\zeta(1-\xi)\left(v_{1}^{y}\right)^{\xi} \\
& \frac{P_{t+1}^{x}}{P_{t}^{x}}=\frac{V_{t+1}^{x}}{V_{t}^{x}} \frac{c_{t}^{x}}{c_{t+1}^{x}} \frac{M_{t+2}^{x}}{M_{t+1}^{x}} \\
& \frac{P_{t+1}^{y}}{P_{t}^{y}}=\frac{v_{t+1}^{y}}{v_{t}^{y}} \frac{c_{t}^{y}}{c_{t+1}^{y}} \frac{M_{t+2}^{y}}{M_{t+1}^{y}} .
\end{aligned}
$$

The next step is to formally characterize $\mathrm{R}_{t+1}$, the return to the aggregate wealth portfolio. Since we define the return to money inclusive of marginal transaction costs, $\psi_{2,5}^{x}$ and $\psi_{2,1}^{y}$ we must incorporate these marginal transaction costs into the definition of the portfolio weights for the aggregate wealth portfolio. Formally, let 


$$
\hat{W}_{1} \equiv W_{1}-\left[c_{1}^{x}+\psi_{1}^{x}+S_{1} \frac{P_{1}^{y}}{P_{1}^{x}}\left(c_{1}^{y}+\psi_{1}^{y}\right)\right]+\frac{M_{1+1}^{x}}{P_{1}^{x}} \psi_{21}^{x}+S_{1} \frac{M_{1+1}^{y}}{P_{1}^{x}} \psi_{2 t}^{y}
$$

$\hat{W}_{t}$ denotes wealth available for asset purchases at date $t$, adjusted for marginal transaction costs. The portfolio weights on the aggregate wealth portfolio are defined in terms of $\hat{W}_{1}$. Let $w_{x, t+1}$ and $w_{y, t+1}$ denote the portfolio weight on $M_{t+1}^{x}$ and $M_{t+1}^{y}$, respectively:

$$
\begin{aligned}
& \left.w_{2, s+1} \equiv\left[\frac{M_{t+1}^{x}}{P_{t}^{x}}\left(1+\psi_{20}^{x}\right)\right)\right] \hat{W}_{t} \\
& w_{y, 1+1} \equiv\left[S_{t} \frac{M_{1+1}^{y}}{P_{t}^{x}}\left(1+\psi_{2 x}^{y}\right)\right] \hat{W}_{t} .
\end{aligned}
$$

Let $w_{i,+1}$ denote the portfolio weight on asset $i$ :

$$
w_{i s+1} \equiv \frac{z_{i s+1}}{\hat{w}_{1}}, \quad i=1, \ldots, N
$$

Note that the weights sum to unity:

$$
\sum_{i=1}^{N} w_{1, x+1}+w_{x x+1}+w_{y, t+1}=1
$$

The return to the aggregate wealth portfolio is defined as follows:

$$
R_{t+1} \equiv \sum_{i=1}^{N} w_{L i+1} R_{i x+1}+w_{x, t+1} R_{2, x+1}+w_{y, t+1} R_{y, t+1}
$$

where $R_{\iota,+1+1}$ and $R_{y,+1}$ are defined in equations (22) and (23). Aggregate wealth evolves according to 


$$
W_{1+1}=\hat{W}_{1} R_{1+1}
$$

In a single-good nonmonetary model, the market retum can be expressed as a function of the wealth/consumption ratio and the growth rate of consumption. It is convenient to express $R_{1+1}$ in a similar way. To do so, define $\bar{c}_{1} \equiv W_{1}-\hat{W}_{1}$, and let the "wealth/consumption ratio" $W / c_{1}$ be denoted $w c_{l}$. Equation (46) then implies

$$
R_{t+1}=\frac{w c_{1+1}\left(c_{1+1} / c_{1}\right)}{w c_{1}-1}
$$

The transaction cost functions $\psi^{x}$ and $\psi^{y}$ are homogeneous of degree one, so one can use Euler's theorem, along with equation (30), to show that

$$
\left(\frac{\bar{c}_{1+1}}{\bar{c}_{1}}\right)=\left(\frac{c_{1,1}^{x}}{c_{1}^{x}}\right)\left(\frac{1+\psi_{1, t+1}^{x}}{1+\psi_{1, x}^{x}}\right) .
$$

By using equations (32) - (39) and equation (48) in equations (22), (23), (26), and (47), one can write the endogenous processes $R_{x,+1}, R_{y,+1}, Z_{1+1}$, and $R_{1+1}$ as functions of $\left\{g_{t+1}, v_{1}^{x}, v_{1+1}^{x}, v_{1}^{y}, v_{i+1}^{y}\right.$, $w c_{n} w c_{1+1}$ ). It follows that the three-equation system consisting of equation (24) and equation (25) with $i=x$ and $i=y$, can be expressed in terms of $\left(g_{t+1}, v_{1}^{x}, v_{i+1}^{x}, v_{1}^{y}, v_{i+1}^{y}, w c_{1}, w c_{i+1}\right)$. Let this three-equation system be denoted

$$
E_{1}\left[f\left(g_{t+1}, v_{t+1}^{x}, v_{1}^{x}, v_{t+1}^{y}, v_{1}^{y}, w c_{1+1}, w c_{1}\right)\right]=0
$$

where $f$ is a known function.

Our task then is to find a stochastic process $\left(v_{1}^{x}, v_{1}^{y}, w c_{l}\right\}$ which satisfies equations (49) for the given $g_{1}$ process. Following Tauchen and Hussey (1991), we approximate $g_{t}$ by a finite- 
state Markov chain. The discretization uses Gaussian quadrature. In the results presented in section 7, we allow each of the four elements of g to take on 4 values, implying 256 possible states of the economy. The endogenous processes, $v_{t}^{x}, v_{t}^{y}, w c_{v}$ are then represented by vectors with 256 elements each, to be determined by solving system (49). The conditional expectation can be evaluated exactly (given the discrete approximation) since the state transition probabilities are known. We reduce the computational burden of this solution algorithm by assuming that the growth rates of $c_{t}^{1}$ and $c_{t}^{y}$ are observed, rather than the growth rates of output in the two countries. This enables us to solve system (49) recursively: the elements of $\left\{w c_{v}, v_{x}\right\}$ do not depend on the third equation in (49). Therefore, the 512 elements of $\left\{w c_{v}, v_{x}\right\}$ are found by simultaneously solving the 512 equations represented by the first two equations of (49), each evaluated at each of the 256 states. Given these values for $\left\{w c_{1}, v_{z}\right\}$, the 256 elements of $v_{y}$ are found by soiving the 256 equations represented by the last equation of (49) evaluated at each of the 256 states. Having solved for $\left(w c_{1}, v_{2}, v_{y}\right)$, the remaining endogenous variables can be computed using equation (47) and equations (32) - (39). 


\section{References}

Backus, D., A. Gregory and C. Telmer, 1993, "Accounting for Forward Rates in Markets for Foreign Currency", Joumal of Finance 48, 1887-1908.

Bansal, R., A. R. Gallant, R.Hussey and G. Tauchen, 1991, "Nonparametric Structural Estimation of Models for High-Frequency Currency Market Data," manuscript, Duke University.

Bekaert, G., 1992, "The Time-Variation of Expected Retums and Volatility in Foreign Exchange Markets," Working Paper No. 1226, Stanford University, Graduate School of Business.

Bekaert, G., 1993a, "Exchange Rate Volatility and Deviations from Unbiasedness in a Cash-inAdvance Model," Journal of International Economics forthcoming.

Bekaert, G., 1993b, "The Time Variation of Risk and Return in Foreign Exchange Markets: A General Equilibrium Approach," Working Paper No. 1276, Stanford University, Graduate School of Business.

Bekaert, G. and R. Hodrick, 1992, "Characterizing Predictable Components in Excess Retums on Equity and Foreign Exchange Markets," Journal of Finance 47, 467-509.

Bekaert, G. and R. Hodrick, 1993, "On Biases in the Measurement of Foreign Exchange Risk Premiums," Joumal of International Money and Finance 12, 115-138.

Bera, A. K. and C. M. Jarque, 1982, "Model Specification Tests: A Simultaneous Approach," Journal of Econometrics 20, 59-82.

Bonomo, M. and R. Garcia, 1993, "Disappointment Aversion as a Solution to the Equity Premium and the Risk-Free Rate Puzzles," Cahier 2793, Universite de Montreal.

Bossaerts, P. and P. Hillion, 1991, "Market Microstructure Effects of Government Intervention in the Foreign Exchange Market," Review of Financial Studies 4, 513-541.

Camerer, C.F., 1989, "Recent Tests of Generalizations of Expected Utility Theory," manuscript.

Cochrane, J. and L. Hansen, 1992, "Asset Pricing Explorations for Macroeconomics," NBER Macroeconomics Annual 1992 7, 115-165.

Cumby, R. E. and J. Huizinga, 1992, "Testing the Autocorrelation Structure of Disturbances in Ordinary Least Squares and Instrumental Variables Regressions, Econometrica 60, 185-196.

Engel, C., 1992, "On the Foreign Exchange Risk Premium in a General Equilibrium Model," Joumal of International Economics 32, 305-319. 
Epstein, L. and S. Zin, 1989, "Substitution, Risk Aversion and the Temporal Behavior of Consumption and Asset Returns, Econometrica 57, 937-969.

Epstein, L. and S. Zin, 1990, "First-Order' Risk Aversion and the Equity Premium Puzzle," Journal of Monetary Economics 26, 387-407.

Epstein, L. and S. Zin, 1991, "The Independence Axiom and Asset Returns," NBER Technical Working Paper No. 109.

Fama, E., 1984a, "Forward and Spot Exchange Rates," Joumal of Monetary Economics 14, 319338.

Fama, E., 1984b, "The Information in the Term Structure," Joumal of Financial Economics 13, 509-528.

Feenstra, R., 1986, "Functional Equivalence Between Liquidity Costs and the Utility of Money," Joumal of Monetary Economics 17, 271-291.

Gul, F., 1991, "A Theory of Disappointment Aversion," Econometrica 59, 667-710.

Hall, R. E., 1988, "Intertemporal Substitution in Consumption," Joumal of Political Economy 96, 339-357.

Hansen, L. P., 1982, "Large Sample Properties of Generalized Method of Moments Estimators," Econometrica 50, 1029-1054.

Hansen, L. and R. Hodrick, 1980, "Forward Rates as Predictors of Future Spot Rates," Journal of Political Economy 88, 829-853.

Hansen, L. P., and R. Jagannathan, 1991, "Implications of Security Market Data for Models of Dynamic Economies," Joumal of Political Economy 99, 225-262.

Hansen, L. P. and S. Richard, 1987, "The Role of Conditioning Information in Deducing Testable Restrictions Implied by Dynamic Asset Pricing Models," Econometrica 55, 587-613.

Hansen, L. P. and K. Singleton, 1982, "Generalized Instrumental Variables Estimation of Nonlinear Rational Expectations Models," Econometrica 50, 1269-1286.

Harvey, C. R., 1991, "The World Price of Covariance Risk," Journal of Finance 46, March 1991. $111 \cdot 155$.

Heaton, J., 1991, "An Empirical Investigation of Asset Pricing with Temporally Dependent Preference Specifications," Manuscript, M.I.T. 
Hodrick, R.,1992, "An Interpretation of Foreign Exchange Market Efficiency Tests," manuscript, Kellogg Graduate School of Management, Northwestem University.

Kandel and Stambaugh, 1991, "Asset Retums and Intertemporal Preferences," Journal of Monetary Economics 27, 39-71.

Marshall, D., 1992, "Inflation and Asset Returns in a Monetary Economy," Joumal of Finance 47, $1315-1342$.

Newey, W. and K. West, 1987, "A Simple, Positive Semi-definite, Heteroskedasticity and Autocorrelation Consistent Covariance Matrix," Econometrica 55, 703-708.

Roll, R. 1977, "A Critique of the Asset Pricing Theory's Tests, Part I" Joumal of Financial Economics 4, 129-176.

Segal, U. and A. Spivak, 1990, "First-Order versus Second-Order Risk Aversion," Joumal of Economic Theory 51, 111-125.

Sims, C., 1980, "Macroeconomics and Reality." Econometrica 48, 1-49.

Solnik, B., 1993, "The Performance of International Asset Allocation Strategies Using Conditioning Information," Journal of Empirical Finance 1, 33-55.

Stambaugh, R. 1988, "The Information in. Forward Rates: Implications for Models of the Term Structure," Journal of Financial Economics 21, 41-70.

Tauchen, G. and Hussey, 1991, "Quadrature-Based Methods for Obtaining Approximate Solutions to Nonlinear Asset Pricing Models," Econometrica 59, 371-396. 
Table 1

Panel A: Regression Results

\begin{tabular}{|c|c|c|c|c|c|}
\hline $\begin{array}{l}\text { Dependent } \\
\text { Variable }\end{array}$ & $\begin{array}{l}\text { Coef. on } \\
\text { constant }\end{array}$ & $\begin{array}{l}\text { Coef. } \\
\text { on } \mathrm{fp}_{\mathrm{t}}\end{array}$ & $\begin{array}{c}\text { Coef. on } \\
\mathrm{fb}_{\mathrm{t}}^{\mathrm{s}}\end{array}$ & $\begin{array}{c}\text { Coef. on } \\
\mathrm{fb}_{\mathrm{t}}^{\mathrm{v}}\end{array}$ & $\mathrm{R}^{2}$ \\
\hline$s_{+1}-f_{t}$ & $\begin{array}{l}16.271 \\
(3.674)\end{array}$ & $\begin{array}{l}-4.016 \\
(0.766)\end{array}$ & & & .220 \\
\hline$h_{t+1,2}^{s}-i_{i}^{s}$ & $\begin{array}{c}0.038 \\
(0.050)\end{array}$ & & $\begin{array}{l}-0.450 \\
(0.129)\end{array}$ & & .028 \\
\hline$h_{t+1,2}^{y}-i_{1}^{z}$ & $\begin{array}{c}0.075 \\
(0.019)\end{array}$ & & & $\begin{array}{l}-0.448 \\
(0.028)\end{array}$ & .086 \\
\hline$r_{1+1}^{*} \cdot i_{1}^{s}$ & $\begin{array}{l}21.540 \\
(4.864)\end{array}$ & $\begin{array}{l}-3.543 \\
(0.816)\end{array}$ & & & .139 \\
\hline$r_{1+1}^{s}-i_{1}^{s}$ & $\begin{array}{l}11.413 \\
(4.971)\end{array}$ & $\begin{array}{l}-2.024 \\
(0.900)\end{array}$ & & & .041 \\
\hline$r_{t+1}^{v} \cdot i_{1}^{v}$ & $\begin{array}{l}15.397 \\
(4.807)\end{array}$ & $\begin{array}{l}-1.045 \\
(0.954)\end{array}$ & & & .013 \\
\hline
\end{tabular}


Table 1 (continued)

Panel B: Means and Standard Deviations

\begin{tabular}{|c|c|c|}
\hline Variable & Mean & $\begin{array}{l}\text { Standard } \\
\text { Deviation }\end{array}$ \\
\hline$\Delta \mathrm{s}_{\mathrm{l}+1}$ & 5.119 & 25.019 \\
\hline$f p_{i}$ & 3.698 & 3.077 \\
\hline fitted $s_{t+1}-f_{t}$ & 1.421 & 12.355 \\
\hline $\mathrm{fb}_{\mathrm{i}}^{\mathrm{s}}$ & 0.124 & 0.707 \\
\hline$h_{t+1,2}^{s}-i_{t}^{s}$ & 0.094 & 1.892 \\
\hline $\begin{array}{c}\text { fitted } h_{t+1,2}^{s}- \\
i_{t}^{s} \\
\end{array}$ & 0.094 & 0.318 \\
\hline $\mathrm{fb}_{\mathrm{i}}^{*}$ & 0.116 & 0.826 \\
\hline$h_{i+1,2}^{*}-i_{i}^{k}$ & 0.128 & 1.259 \\
\hline $\begin{array}{c}\text { fitted } h_{t+1,2}^{*}- \\
i_{t}^{Y}\end{array}$ & 0.128 & 0.370 \\
\hline$r_{1.1}^{n}-i_{1}^{s}$ & 8.440 & 29.204 \\
\hline fitted $r_{t, 1}^{w}-i_{t}^{s}$ & 8.440 & 10.899 \\
\hline
\end{tabular}

Notes: The data are monthly observations on quarterly rates. The sample period is from January 1976 to December 1989 for exchange rates and equities and from October 1975 to June 1990 for interest rates. All rates are measured as percentage points per annum. Time subscripts denote quarters. The logarithms of the dollar/yen spot and forward exchange rates are denoted $s_{t}$ and f. The quarterly rate of depreciation is $\Delta s_{t+1}$; the three-month forward premium on the yen in terms of the dollar is denoted $\mathrm{fp}_{i}$; the quarterly dollar excess retum on the world equity market (an equally-weighted average of the dollar excess returns to U.S. and Japanese equities, defined in equation (7)) is $r_{t+1}^{*}-i_{i}^{s}$, the three-month dollar excess return to U.S. equities is $r_{t+1}^{s}-i_{i i}^{s}$ the three month yen excess return to Japanese equities is $r_{t+3}^{*}-i_{i ;}^{*} h_{i+1,2}^{s}-i_{i}^{s}\left(h_{i+1,2}^{*}-i_{t}^{*}\right)$ is the quarterly excess dollar (yen) retum from $t$ to $t+1$ obtained by holding dollar (yen) discount bonds that mature at $t+2 ; \mathrm{fb}_{1}^{\mathrm{s}}\left(\mathrm{fb}_{\mathrm{t}}^{\mathrm{k}}\right)$ is the one-quarter-ahead forward premium, defined in equation (5), in the dollar (yen) discount bond market. In Panel $B$, the variable "fitted $s_{t+1}-f_{t}$ " is the fitted value of regression (2); the variable "fitted $h_{t+1,2}^{s}-i_{t}^{s " 1}$ ("fitted $h_{t+1,2}^{\psi}-i_{l}^{\psi(n)}$ ) is the fitted value of regression (6) using data from the dollar (yen) bond market; the variable "fitted $r_{i+1}^{*}-i_{i}^{\text {s" }}$ is the fitted value of regression (8). The numbers in parentheses are standand errors, which are heteroskedasticityconsistent and are corrected for the serial correlation induced by the overlap in the data using the method of Newey and West (1987). 
Table 2

VAR Estimates and Diagnostics for the Exogenous Processes

Panel A: Parameter Estimates for the VAR

\begin{tabular}{ccccccc} 
& $\begin{array}{c}\text { constan } \\
\mathrm{t}\end{array}$ & $\mathrm{gm}_{\mathrm{i}-1}$ & $\mathrm{gx}_{\mathrm{t-1}}$ & $\mathrm{gn}_{\mathrm{t-1}}$ & $\mathrm{gy}_{\mathrm{t}-1}$ & $\mathrm{R}^{2}$ \\
\hline $\mathrm{gm}$ & .610 & .195 & .022 & -.182 & .368 & .074 \\
& $(.446)$ & $(.151)$ & $(.437)$ & $(.074)$ & $(.184)$ & \\
$\mathrm{gx}$ & .629 & .033 & .281 & -.016 & .076 & .057 \\
& $(.141)$ & $(.038)$ & $(.118)$ & $(.024)$ & $(.062)$ & \\
$\mathrm{gn}_{4}$ & .439 & .023 & 1.310 & -.493 & -.259 & .198 \\
& $(.835)$ & $(.228)$ & $(.763)$ & $(.129)$ & $(.370)$ & \\
$\mathrm{gy}_{1}$ & 1.118 & .137 & -.060 & -.015 & -.171 & .009 \\
& $(.287)$ & $(.085)$ & $(.246)$ & $(.050)$ & $(.142)$ &
\end{tabular}

Panel B: Cholesky Decomposition of the Covariance Matrix of the VAR Residuals

$\begin{array}{cccc}.01261 & .00114 & .00054 & -.00056 \\ (.00152) & (.00034) & (.00287) & (.00073) \\ & .00382 & .00332 & -.00038 \\ & (.00043) & (.00272) & (.00087) \\ & & .02326 & .00371 \\ & & (.00177) & (.00097) \\ & & & .00762 \\ & & & (.00059)\end{array}$


Table 2 (Continued)

Panel C: Selection Criteria for the VAR Order

\begin{tabular}{ccc} 
VAR order & Akaike Criterion & Schwarz criterion \\
\hline 1 & -36.61 & -36.05 \\
2 & -36.45 & -35.33 \\
3 & -36.43 & -34.74
\end{tabular}

1 vs. $219.06(.266)$

2 vs. $323.94(.091)$

Panel D: Residual Diagnostics

\begin{tabular}{cccccc} 
& $1(4)$ & Q2(4) & Ku & Sk & BJ \\
\hline Eq. 1 & 2.481 & 5.916 & .172 & .005 & 0.075 \\
& $(.894)$ & $(.206)$ & $(.784)$ & $(.987)$ & $(.963)$ \\
Eq. 2 & 6.110 & 7.039 & 1.137 & -.046 & 3.308 \\
& $(.191)$ & $(.134)$ & $(.070)$ & $(.883)$ & $(.191)$ \\
Eq. 3 & 7.198 & 4.036 & -.547 & .200 & 1.169 \\
& $(.126)$ & $(.401)$ & $(.383)$ & $(.523)$ & $(.558)$ \\
Eq. 4 & 14.27 & 2.123 & -.500 & .232 & 1.182 \\
& $(.007)$ & $(.713)$ & $(.426)$ & $(.459)$ & $(.554)$
\end{tabular}

Notes: The sample period is $1974: 4$ to $1990: 1$. gm, denotes the growth rate of the dollar money supply; gx, denotes the growth rate of U.S. consumption; gn, denotes the growth rate of the yen money supply; gy, denotes the growth rate of Japanese consumption. Estimates of the VAR coefficients and the decomposition of the error covariance matrix are obtained by OLS and reported in Panels A and B with heteroskedasticity-consistent standard errors in parentheses. The appropriate lag length for the VAR minimizes the Akaike or Schwarz criterion in Panel C. The likelithood ratio test is a sequential test of a VAR(n) versus a VAR(n+1). The test statistic has a $\chi^{2}$ distribution with degrees of freedom equal to the number of coefficients being restricted by the lower VAR order. The statistic incorporates the Sims (1980) correction. Marginal levels of significance are in parentheses. Panel D reports statistics and associated p-values for various residual diagnostic tests. Column 1 reports the Cumby-Huizinga (1992) 1-test for serial correlation of the residuals. Column 2 reports the Ljung-Box test statistic, applied to squared residuals, as a test for ARCH. Columns 3, 4, and 5 test for normality of the residuals. Ku is the normalized kurtosis coefficient and Sk the normalized skewness coefficient. Their asymptotic distribution is $N(0,24 / T), N(0,6 / T)$ respectively, with $T$ the sample size, under the null of normality. BJ is the Bera-Jarque (1982) test for normality and is $\chi^{2}(2)$. 
Table 3

VAR Parameters Induced by the Discretized Markov Chain Approximation

(i) Implied VAR Coefficients

\begin{tabular}{cccccc} 
& $\begin{array}{c}\text { constan } \\
\mathrm{t}\end{array}$ & $\mathrm{gm}_{\mathrm{t}-1}$ & $\mathrm{gx}_{\mathrm{t}-1}$ & $\mathrm{gM}_{\mathrm{i}-1}$ & $\mathrm{gy}_{\mathrm{t}-1}$ \\
\hline $\mathrm{gm}$ & .610 & .194 & .022 & -.181 & .368 \\
$\mathrm{gx}$ & .629 & .033 & .280 & -.016 & .075 \\
$\mathrm{gm}$ & .443 & .023 & 1.299 & -.489 & -.255 \\
$\mathrm{gy}_{1}$ & 1.118 & .137 & -.062 & -.014 & -.170
\end{tabular}

(ii) Cholesky Decomposition of the Implied Residual Covariance Matrix

$\begin{array}{llll}.01261 & .00114 & .00054 & -.00056 \\ & .00382 & .00331 & -.00038 \\ & & .02312 & .00369 \\ & & & .00762\end{array}$

Notes: The discrete state space approximation to the VAR in Table 2 is computed using the Gaussian quadrature procedure of Tauchen and Hussey (1991). Each variable is allowed to take four possible values, implying a discrete state space with 256 elements. Variable definitions are given in the notes to Table 2 . 
Table 4

Implications of the Model for the Foreign Exchange Market Regression

\begin{tabular}{|c|c|c|c|c|c|c|c|}
\hline & & $A=1.0$ & $A=.85$ & $A=.70$ & $A=.55$ & $A=$ & $\mathrm{A}=.25$ \\
\hline \multirow{5}{*}{$\rho=.5$} & $\beta_{1}$ & -.007 & -.012 & -.068 & -.097 & .038 & -.191 \\
\hline & $\mathbf{R}^{2}$ & $1.0 \times 10^{7}$ & $2.1 \times 10^{-5}$ & $8.8 \times 10^{-5}$ & .00016 & 00030 & .00133 \\
\hline & б[P] & .003 & .042 & .085 & .116 & .159 & .332 \\
\hline & $\sigma\left[E_{t}\left(\Delta s_{t+1}\right)\right]$ & .228 & .229 & .226 & .230 & .274 & .370 \\
\hline & $\operatorname{cov}\left[\mathrm{rp}_{1}, \mathrm{E}_{\mathrm{l}}\left(\Delta \mathrm{s}_{\mathrm{l}+1}\right)\right]$ & $\cdot .0004$ & .0011 & .0038 & .0087 & .0269 & .1017 \\
\hline \multirow{5}{*}{$\rho=-.33$} & $\beta_{1}$ & -.007 & -.023 & -.057 & -.107 & .035 & .044 \\
\hline & $\mathrm{R}^{2}$ : & $1.0 \times 10^{7}$ & $1.8 \times 10^{-5}$ & $7.7 \times 10^{-5}$ & .00015 & .00029 & .00116 \\
\hline & $\sigma[\mathrm{TP}]$ & .003 & .039 & .080 & .113 & .155 & .309 \\
\hline & $\sigma\left[E_{t}\left(\Delta s_{t+1}\right)\right]$ & .236 & .231 & .229 & .228 & .269 & .363 \\
\hline & $\operatorname{cov}\left[\mathrm{p}_{1}, \mathrm{E}_{\mathrm{l}}\left(\Delta \mathrm{s}_{\mathrm{l}+1}\right)\right]$ & -.0004 & .0003 & .0034 & .0076 & .0256 & .0941 \\
\hline \multirow{5}{*}{$\rho=-3$} & $\beta_{1}$ & -.001 & -.003 & -.006 & -.021 & -.009 & .057 \\
\hline & $\mathbf{R}^{2}$ & $1.0 \times 10^{-7}$ & $2.1 \times 10^{.5}$ & $8.6 \times 10^{-5}$ & .00017 & .00032 & .00133 \\
\hline & $\sigma[\mathrm{rPJ}]$ & .003 & .042 & .085 & .118 & .164 & .334 \\
\hline & $\sigma\left[E_{l}\left(\Delta s_{t+1}\right)\right]$ & .485 & .472 & .461 & .443 & .438 & .509 \\
\hline & $\operatorname{cov}\left[\mathrm{p}_{0}, \mathrm{E}_{1}\left(\Delta \mathrm{s}_{t+1}\right)\right]$ & -.0001 & .0011 & .0061 & .0099 & .0255 & .1190 \\
\hline \multirow{5}{*}{$\rho=-9$} & $\beta_{1}$ & .001 & .003 & .005 & .007 & .008 & .009 \\
\hline & $\mathbf{R}^{2}$ & $1.7 \times 10^{7}$ & $2.1 \times 10^{-5}$ & $8.2 \times 10^{-5}$ & .00015 & .00032 & .00138 \\
\hline & $\sigma[\mathrm{pl}]$ & .004 & .044 & .088 & .120 & .173 & .356 \\
\hline & $\sigma\left[E_{t}\left(\Delta s_{t+1}\right)\right]$ & 2.284 & 2.200 & 2.100 & 1.973 & 1.807 & 1.575 \\
\hline & $\operatorname{cov}\left[\mathrm{rp}_{t}, \mathrm{E}_{\mathrm{t}}\left(\Delta \mathrm{s}_{t+1}\right)\right]$ & .0046 & .0157 & .0311 & .0422 & .0570 & .1472 \\
\hline
\end{tabular}

Notes: The logarithms of the dollar/yen spot and forward exchange rates are denoted $s_{1}$ and $f_{1}$, and $\quad \mathrm{TP}_{t}=\mathrm{E}_{\mathrm{t}}\left(\mathrm{s}_{\mathrm{t}+1}-\mathrm{f}_{\mathrm{l}}\right)$. $\quad \beta_{1}$ denotes the slope coefficient in the regression $s_{1+1}-f_{1}=\beta_{0}+\beta_{1}\left(f_{t}-s_{t}\right)+\varepsilon_{t+1}$. $E_{t}\left(x_{t+1}\right)$ denotes the expectation of $x_{t+1}$ conditional on date $t$ information, $\sigma\left[x_{l}\right]$ denotes the unconditional standard deviation of $x_{l}$, and $\operatorname{cov}\left[x_{t}, y_{l}\right]$ denotes the unconditional covariance. $R^{2}=\operatorname{var}\left(E_{t}\left(s_{1+1}-f_{2}\right)\right) / \operatorname{var}\left(s_{1+1}-f_{2}\right)$. All moments reported are the exact population moments implied by the model at the indicated parameter specifications, given the Markov transition matrix for the exogenous process $g$. This transition matrix was computed using Gaussian quadrature from the estimated VAR, as described in Appendix B. 
Table 5

Implications of the Model for the Dollar Discount Bond Market Regression

\begin{tabular}{|c|c|c|c|c|c|c|c|}
\hline & & $A=1.0$ & $A=.85$ & $\mathrm{~A}=.70$ & $A=.55$ & $A=.40$ & $\mathrm{~A}=.25$ \\
\hline \multirow{5}{*}{$p=.5$} & $\beta_{1}$ &. .00001 & -.00022 & -.00026 & .00013 &. .00196 & .00084 \\
\hline & $\mathbf{R}^{2}$ & $1.0 \times 10^{-9}$ & $7.7 \times 10^{6}$ & $2.6 \times 10^{-5}$ & $5.4 \times 10^{-5}$ & .00014 & .00053 \\
\hline & $\sigma\left(t_{t}^{3}\right)$ & .00003 & .00067 & .00121 & .00172 & .00272 & .00512 \\
\hline & $E_{1}\left[\Delta v_{1+1}^{3}\right]$ & .220 & .218 & .215 & .211 & .206 & .199 \\
\hline & $\operatorname{cov}\left[t_{1}^{3}, E_{1}\left(\Delta v_{t+1}^{3}\right)\right]$ & $-5.0 \times 10^{7}$ & $-1.0 \times 10^{5}$ & $-1.0 \times 10^{5}$ & $8.6 \times 10^{6}$ & $-7.6 \times 10^{3}$ & $-7.2 \times 10^{6}$ \\
\hline \multirow{5}{*}{$\rho=-.33$} & $\beta_{1}$ & .00005 & .00042 & .00031 & .00046 & .00048 & -.00205 \\
\hline & $\mathbf{R}^{2}$ : & $5.0 \times 10^{-4}$ & $1.4 \times 10^{5}$ & $5.1 \times 10^{-5}$ & .00012 & .00024 & .00087 \\
\hline & $\sigma\left(p_{t}^{3}\right)$ & .00005 & .00078 & .00146 & .00219 & .00297 & .00528 \\
\hline & $E_{[}\left[\Delta v_{l+1}^{A}\right]$ & .230 & .226 & .221 & .214 & .206 & .192 \\
\hline & $\operatorname{cov}\left[\mathrm{t}_{1}^{3}, \mathrm{E}_{\mathrm{l}}\left(\Delta v_{t+1}^{3}\right)\right]$ & $3 \times 10^{6}$ & $-2.2 \times 10^{-5}$ & .00013 & $2.6 \times 10^{-3}$ & $2.9 \times 10^{3}$ & $-4.8 \times 10^{5}$ \\
\hline \multirow{5}{*}{$\rho=-3$} & $\beta_{1}$ & -.00006 &. .00031 & -.00113 & -.00128 & -.00122 & -.00491 \\
\hline & $\mathbf{R}^{2}$ & $4.0 \times 10^{-8}$ & $4.7 \times 10^{6}$ & $2.2 \times 10^{-3}$ & $4.9 \times 10^{-5}$ & .00010 & .00034 \\
\hline & $\sigma\left(\omega_{1}^{3}\right)$ & .0002 & .0021 & .0044 & .0062 & .0083 & .0135 \\
\hline & $E_{i}\left[\Delta v_{i+1}^{d}\right]$ & 1.109 & 1.074 & 1.030 & .977 & .910 & .805 \\
\hline & $\left.\operatorname{cov}\left[r_{1}^{3}\right), E_{1}\left(\Delta v_{t+1}^{s}\right)\right]$ & -.00007 & -.00036 & .00118 & -.00119 & -.00095 & 0.00303 \\
\hline \multirow{5}{*}{$\rho=-9$} & $\beta_{1}$ & -.0001 & .0006 & -.0012 & -.0018 & -.0025 & -.0047 \\
\hline & $\mathbf{R}^{2}$ & $1.1 \times 10^{-6}$ & $1.9 \times 10^{3}$ & $7.4 \times 10^{-5}$ & .00019 & .00045 & .00112 \\
\hline & $\sigma\left(b_{t}^{5}\right)$ & .006 & .024 & .045 & .067 & .093 & .123 \\
\hline & $E_{i}\left[\Delta v_{t+1}^{s}\right]$ & 5.995 & 5.725 & 5.406 & 5.016 & 4.516 & 3.798 \\
\hline & $\operatorname{cov}\left[\left(t_{t}^{3}\right), E_{l}\left(\Delta v_{t+1}^{3}\right)\right]$ & -.0047 & -.0176 & -.0318 & -.0421 & -.0342 & -.0528 \\
\hline
\end{tabular}

Notes: $h_{1+1,2}^{3}$ denotes the continuously compounded one-period holding period return on twoperiod dollar discount bonds; $i_{i}^{s}$ denotes the continuously compounded dollar spot interest rate; $\Delta v_{t+1}^{s}$ denotes the rate of change in the logarithm of the price of one-period dollar bonds; and $x b_{1}^{3}$ $=E_{1}\left(h_{t+1,2}^{3}-i_{t}^{3}\right)$. $\beta_{1}$ denotes the slope coefficient in the regression $h_{1+1,2}^{3}-i_{1}^{3}=\beta_{0}+\beta_{1}\left(f b_{l}{ }^{3}\right)+\varepsilon_{t+1}$. $R^{2}=\operatorname{var}\left(E_{t}\left(h_{i+1,2}^{s}-i_{1}{ }^{5}\right) / \operatorname{var}\left(h_{t+1,2}^{3}-i_{i}^{3}\right)\right.$. See also the note to Table 4. 
Table 6

Implications of the Model for the Yen Discount Bond Market Regression

\begin{tabular}{|c|c|c|c|c|c|c|c|}
\hline & & $A=1.0$ & $A=.85$ & $A=.70$ & $\mathrm{~A}=.55$ & $A=.40$ & $A=.25$ \\
\hline \multirow{5}{*}{$\rho=.5$} & $\beta_{1}$ & -.00013 & .00002 & -.00044 & -.00052 & .00214 & .00169 \\
\hline & $R^{2}$ & $2.0 \times 10^{-7}$ & $5.0 \times 10^{-5}$ & .00012 & .00024 & .00054 & .00195 \\
\hline & $\sigma\left(r b_{t}^{y}\right)$ & .00007 & .00091 & .00176 & .00247 & .00352 & .00658 \\
\hline & $\sigma\left[E_{2}\left(\Delta v_{1+1}^{\mathbf{y}}\right)\right]$ & .249 & .247 & .243 & .238 & .230 & .223 \\
\hline & $o v\left[r b_{t}^{v}, E_{l}\left(\Delta v_{t+1}^{v}\right)\right]$ & $-8 \times 10^{-6}$ & $2 \times 10^{-6}$ & $-2.3 \times 10^{-5}$ & $-2.3 \times 10^{-}$ & .000126 & .000127 \\
\hline \multirow{5}{*}{$\rho=-.33$} & $\beta_{1}$ & -.00021 & -.00024 & -.00095 & -.00118 & .00059 & -.00036 \\
\hline & $\mathrm{R}^{2}:$ & $3.5 \times 10^{-7}$ & $3.1 \times 10^{-5}$ & .00013 & .00027 & .00059 & .00193 \\
\hline & $\sigma\left(r_{b}^{y}\right)$ & .00012 & .00113 & .00226 & .00313 & .00442 & .00757 \\
\hline & $\sigma\left[E_{1}\left(\Delta v_{1+1}^{y}\right)\right]$ & .347 & .340 & .333 & .322 & .306 & .288 \\
\hline & $\left.o v\left[r b_{\imath}^{v}\right) E_{r}\left(\Delta v_{1+1}^{v}\right)\right]$ & $-2 \times 10^{6}$ & $-3 \times 10^{-6}$ & -.00010 & -.00011 & .00007 & .00003 \\
\hline \multirow{5}{*}{$\rho=-3$} & $\beta_{1}$ & -.00027 & -.00081 & -.00176 & -.00256 & -.00276 & -.00532 \\
\hline & $\mathrm{R}^{2}$ & $3.2 \times 10^{-7}$ & $1.2 \times 10^{-5}$ & $4.8 \times 10^{5}$ & .00010 & .00020 & .00067 \\
\hline & $\sigma\left(r_{b}^{\mathbf{y}}\right)$ & .0004 & .0023 & .0045 & .0062 & .0080 & .0131 \\
\hline & $\sigma\left[\mathrm{E}_{\mathrm{i}}\left(\Delta \mathrm{v}_{1+1}^{\mathrm{v}}\right)\right]$ & .950 & .919 & .883 & .836 & .774 & .690 \\
\hline & $\operatorname{ov}\left[r b_{1}^{y}, E_{3}\left(\Delta v_{1+1}^{*}\right)\right]$ & -.00024 & -.00068 & -.00136 & -.00176 & -.00160 & -.00239 \\
\hline \multirow{5}{*}{$\rho=-9$} & $\beta_{1}$ & -.0003 & -.0009 & -.0017 & -.0028 & -.0039 & -.0065 \\
\hline & $\mathrm{R}^{2}$ & $7.2 \times 10^{-7}$ & $1.4 \times 10^{-5}$ & $5.3 \times 10^{-5}$ & .00013 & .00029 & .00073 \\
\hline & $\sigma\left(r_{1}^{y}\right)$ & .036 & .013 & .024 & .034 & .046 & 0628 \\
\hline & $\sigma\left[\mathrm{E}_{\mathbf{r}}\left(\Delta \mathrm{v}_{\mathrm{t}+1}^{\mathrm{y}}\right)\right]$ & 4.062 & 3.872 & 3.648 & 3.374 & 3.025 & 2.541 \\
\hline & $o v\left[r b_{l,}^{y}, E_{l}\left(\Delta v_{t+1}^{*}\right)\right]$ & 0.00422 & -.01396 & -.02262 & -.03069 & -.03398 & -.03876 \\
\hline
\end{tabular}

Notes: $h_{1+1,2}^{\mathbf{v}}$ denotes the continuously compounded one-period holding period return on twoperiod yen discount bonds; $i_{i}^{z}$ denotes the continuously compounded yen spot interest rate; $\Delta \mathbf{v}_{i+1}^{\mathbf{y}}$ denotes the rate of change in the logarithm of the price of one-period yen bonds; and $\mathrm{rb}_{\mathrm{i}}^{\mathbf{r}}=$ $E_{i}\left(h_{t+1,2}^{y} i_{t}^{*}\right)$. $\beta_{1}$ denotes the slope coefficient in the regression $h_{t+1,2}^{*}-i_{t}^{*}=\beta_{0}+\beta_{1}\left(f b_{t}^{y}\right)+\varepsilon_{t+1}$. $R^{2}=\operatorname{var}\left(E_{1}\left(h_{i+1,2}^{5}-i_{i}{ }^{5}\right) / \operatorname{var}\left(h_{i+1,2}^{5}-i_{i}^{5}\right)\right.$. See also the note to Table 4. 
Table 7

Implications of the Model for the Excess Dollar Return on Aggregate Wealth

Panel A: Predictability of Excess Dollar Return on Aggregate Wealth

\begin{tabular}{|c|c|c|c|c|c|c|c|}
\hline & & $A=1.0$ & $A=.85$ & $A=.70$ & $A=.55$ & $A=.40$ & $\mathrm{~A}=.25$ \\
\hline \multirow{3}{*}{$\rho=.5$} & $\beta_{1}$ & -.001 & .003 & -.015 & -.039 & -.034 & -.085 \\
\hline & $\mathrm{R}^{2}$ & $1.0 \times 10^{-8}$ & $4.2 \times 10^{-6}$ & $2.1 \times 10^{-5}$ & $4.6 \times 10^{5}$ & .00012 & .00042 \\
\hline & $\sigma\left[\mathrm{E}_{1}\left(\mathrm{r}_{t+1}-\mathrm{i}_{2}\right)\right]$ & .001 & .013 & .028 & .042 & .068 & .128 \\
\hline \multirow{3}{*}{$\rho=-.33$} & $\beta_{1}$ & -.001 & -.001 & -.004 & -.049 & -.040 & .006 \\
\hline & $\mathrm{R}^{2}$ & $1.0 \times 10^{-4}$ & $3.6 \times 10^{-6}$ & $2.0 \times 10^{-5}$ & $4.6 \times 10^{5}$ & .00011 & .00039 \\
\hline & $\sigma\left[E_{2}\left(r_{1+1}-i\right)\right]$ & .001 & .012 & .028 & .042 & .067 & .123 \\
\hline \multirow{3}{*}{$\rho=-3$} & $\beta_{1}$ & .000 & .002 & .002 & -.008 & -.020 & .025 \\
\hline & $\mathrm{R}^{2}$ & $1.0 \times 10^{2}$ & $3.1 \times 10^{-6}$ & $1.4 \times 10^{5}$ & $3.4 \times 10^{-3}$ & .00010 & .00033 \\
\hline & $\sigma\left[E_{1}\left(r_{t+1}-i_{2}\right)\right]$ & .001 & .012 & .025 & .039 & .068 & .122 \\
\hline \multirow{3}{*}{$\rho=-9$} & $\beta_{1}$ & .001 & .003 & .006 & .010 & .009 & .009 \\
\hline & $\mathrm{R}^{2}$ & $3.7 \times 10^{7}$ & $8.1 \times 10^{-6}$ & $2.8 \times 10^{-5}$ & $7.5 \times 10^{5}$ & .00016 & .00040 \\
\hline & $\sigma\left[\mathrm{E}_{2}\left(\mathrm{r}_{\mathrm{t}+1}-\mathrm{i}_{2}\right)\right]$ & .006 & .028 & .051 & .082 & .115 & .175 \\
\hline
\end{tabular}

Panel B: Mean of $\left(r_{t+1}-i_{j}\right)$

\begin{tabular}{|l|l|l|l|l|l|l|}
\hline & $\mathrm{A}=1.0$ & $\mathrm{~A}=.85$ & $\mathrm{~A}=.70$ & $\mathrm{~A}=.55$ & $\mathrm{~A}=.40$ & $\mathrm{~A}=.25$ \\
\hline$\rho=.5$ & 0.060 & 0.227 & 0.430 & 0.688 & 0.999 & 1.510 \\
\hline$\rho=-.33$ & 0.062 & 0.238 & 0.447 & 0.718 & 1.047 & 1.563 \\
\hline$\rho=-3$ & 0.077 & 0.315 & 0.597 & 0.940 & 1.356 & 1.991 \\
\hline$\rho=-9$ & 0.168 & 0.655 & 1.205 & 1.843 & 2.591 & 3.566 \\
\hline
\end{tabular}

Notes: $r_{t}$ denotes the continuously compounded dollar retum to the aggregate wealth portfolio; $i_{1}$ denotes the continuously compounded dollar spot interest rate. $\beta_{1}$ denotes the slope coefficient in the regression $r_{t+1}-i_{t}=\beta_{0}+\beta_{1}\left(f_{1}-s_{t}\right)+\varepsilon_{t+1} . R^{2}=\operatorname{var}\left(E_{i}\left(r_{i+1}-i_{1}\right)\right) / \operatorname{var}\left(r_{t+1}-i j\right)$. See also the note to Table 4. 


\section{Table 8}

Implications of the Model for Unconditional Standard Deviations

Panel A: $\left(\mathbf{s}_{1+1}-\mathbf{s}_{1}\right)$

\begin{tabular}{||l|l|l|l|l|l|l||}
\hline & $\mathrm{A}=1.0$ & $\mathrm{~A}=.85$ & $\mathrm{~A}=.70$ & $\mathrm{~A}=.55$ & $\mathrm{~A}=.40$ & $\mathrm{~A}=.25$ \\
\hline$\rho=.5$ & 9.118 & 9.121 & 9.122 & 9.125 & 9.110 & 9.093 \\
\hline$\rho=-.33$ & 9.166 & 9.121 & 9.120 & 9.125 & 9.111 & 9.081 \\
\hline$\rho=-3$ & 9.184 & 9.186 & 9.188 & 9.193 & 9.175 & 9.167 \\
\hline$\rho=-9$ & 10.066 & 10.026 & 9.978 & 9.921 & 9.833 & 9.702 \\
\hline
\end{tabular}

Panel B: $\left(f_{1}-s\right)$

\begin{tabular}{||l|l|l|l|l|l|l|}
\hline & $\mathrm{A}=1.0$ & $\mathrm{~A}=.85$ & $\mathrm{~A}=.70$ & $\mathrm{~A}=.55$ & $\mathrm{~A}=.40$ & $\mathrm{~A}=.25$ \\
\hline$\rho=.5$ & .230 & .227 & .225 & .221 & .215 & .209 \\
\hline$\rho=.33$ & .237 & .233 & .228 & .223 & .212 & .198 \\
\hline$\rho=-3$ & .486 & .472 & .456 & .436 & .410 & .364 \\
\hline$\rho=-9$ & 2.282 & 2.193 & 2.087 & 1.955 & 1.784 & 1.521 \\
\hline
\end{tabular}

Panel C: $\left(r_{t+1}-i_{j}\right)$

\begin{tabular}{||l|l|l|l|l|l|l||}
\hline & $\mathrm{A}=1.0$ & $\mathrm{~A}=.85$ & $\mathrm{~A}=.70$ & $\mathrm{~A}=.55$ & $\mathrm{~A}=.40$ & $\mathrm{~A}=.25$ \\
\hline$\rho=.5$ & 6.152 & 6.157 & 6.165 & 6.170 & 6.178 & 6.188 \\
\hline$\rho=-.33$ & 6.230 & 6.235 & 6.240 & 6.249 & 6.255 & 6.254 \\
\hline$\rho=-3$ & 6.802 & 6.791 & 6.782 & 6.765 & 6.741 & 6.714 \\
\hline$\rho=-9$ & 10.002 & 9.850 & 9.672 & 9.458 & 9.163 & 8.746 \\
\hline
\end{tabular}


Table 8 (Continued)

Panel D: $\left(h_{i+1,2}^{s}-i_{i}\right)$

\begin{tabular}{||l|l|l|l|l|l|l||}
\hline & $\mathrm{A}=1.0$ & $\mathrm{~A}=.85$ & $\mathrm{~A}=.70$ & $\mathrm{~A}=.55$ & $\mathrm{~A}=.40$ & $\mathrm{~A}=.25$ \\
\hline$\rho=.5$ & 0.244 & 0.242 & 0.239 & 0.235 & 0.230 & 0.222 \\
\hline$\rho=-.33$ & 0.214 & 0.210 & 0.205 & 0.200 & 0.193 & 0.179 \\
\hline$\rho=-3$ & 0.998 & 0.966 & 0.928 & 0.882 & 0.822 & 0.728 \\
\hline$\rho=-9$ & 5.759 & 5.503 & 5.199 & 4.827 & 4.352 & 3.699 \\
\hline
\end{tabular}

Panel E: $\left(h_{1,1,1}^{i}-i_{i}^{i}\right)$

\begin{tabular}{||l|l|l|l|l|l|l|}
\hline & $\mathrm{A}=1.0$ & $\mathrm{~A}=.85$ & $\mathrm{~A}=.70$ & $\mathrm{~A}=.55$ & $\mathrm{~A}=.40$ & $\mathrm{~A}=.25$ \\
\hline$\rho=.5$ & 0.166 & 0.164 & 0.162 & 0.159 & 0.154 & 0.149 \\
\hline$\rho=-.33$ & 0.206 & 0.202 & 0.197 & 0.191 & 0.182 & 0.172 \\
\hline$\rho=-3$ & 0.697 & 0.674 & 0.647 & 0.612 & 0.567 & 0.505 \\
\hline$\rho=-9$ & 3.685 & 3.510 & 3.304 & 3.054 & 2.735 & 2.292 \\
\hline
\end{tabular}

Notes: See Tables 4-7. 